Discussion

Papers

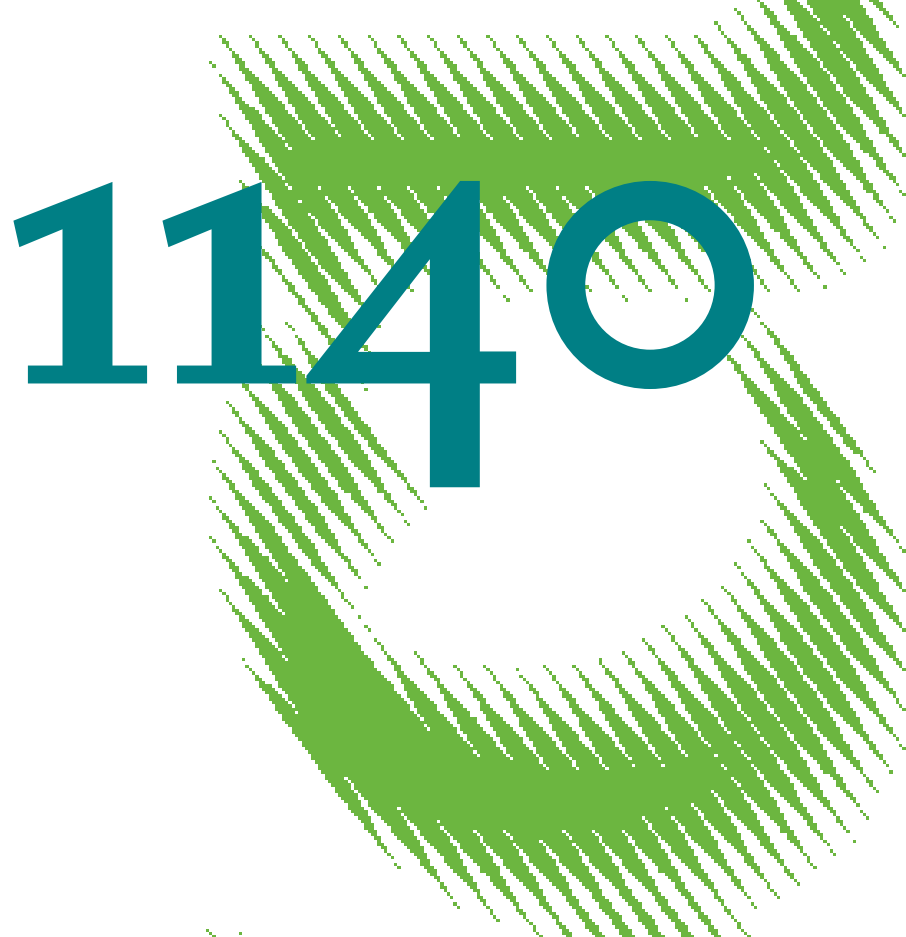

allil

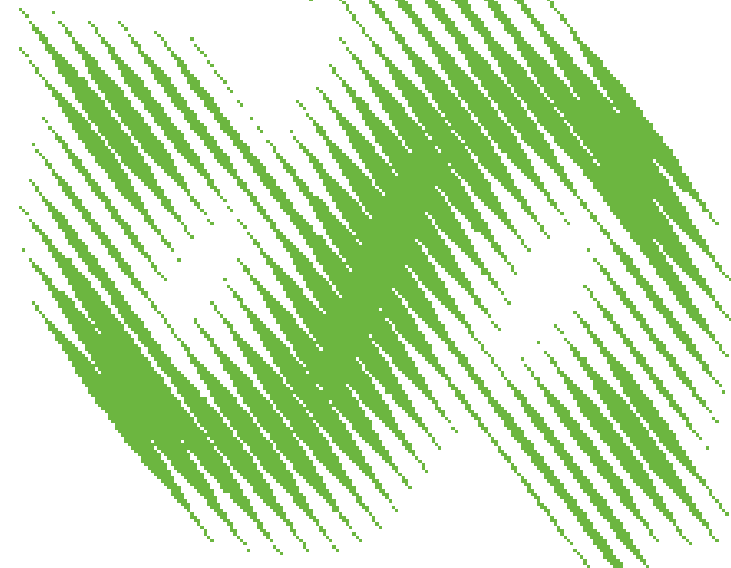

Longevity, Life-cycle Behavior

and Pension Reform 
Opinions expressed in this paper are those of the author(s) and do not necessarily reflect views of the institute.

IMPRESSUM

(C) DIW Berlin, 2011

DIW Berlin

German Institute for Economic Research

Mohrenstr. 58

10117 Berlin

Tel. $+49(30) 89789-0$

Fax +49 (30) $89789-200$

http://www.diw.de

ISSN print edition $1433-0210$

ISSN electronic edition 1619-4535

Papers can be downloaded free of charge from the DIW Berlin website:

http://www.diw.de/discussionpapers

Discussion Papers of DIW Berlin are indexed in RePEc and SSRN:

http://ideas.repec.org/s/diw/diwwpp.html

http://www.ssrn.com/link/DIW-Berlin-German-Inst-Econ-Res.html 


\title{
Longevity, Life-cycle Behavior and Pension Reform*
}

\author{
Peter Haan ${ }^{\dagger}$, Victoria Prowse ${ }^{\ddagger}$
}

July 4, 2011

\begin{abstract}
How can public pension systems be reformed to ensure fiscal stability in the face of increasing life expectancy? To address this pressing open question in public finance, we estimate a life-cycle model in which the optimal employment, retirement and consumption decisions of forward-looking individuals depend, inter alia, on life expectancy and the design of the public pension system. We calculate that, in the case of Germany, the fiscal consequences of the 6.4 year increase in age 65 life expectancy anticipated to occur over the 40 years that separate the 1942 and 1982 birth cohorts can be offset by either an increase of 4.34 years in the full pensionable age or a cut of $37.7 \%$ in the per-year value of public pension benefits. Of these two distinct policy approaches to coping with the fiscal consequences of improving longevity, increasing the full pensionable age generates the largest responses in labor supply and retirement behavior.
\end{abstract}

Keywords: Life Expectancy; Public Pension Reform; Retirement; Employment; Life-cycle Models; Consumption; Tax and Transfer System.

JEL Classification: D91; J11; J22; J26; J64.

${ }^{*}$ The authors thank Richard Blundell, Hippolyte d'Albis, Nicola Fuchs-Schündeln, Johannes Geyer, Eva Kibele, Arne Uhlendorff and seminar participants at Statistics Norway, University of Frankfurt, CREST, University of Cologne, 2011 Netspar International Pension Workshop in Amsterdam, DIW Berlin and the Max Planck Institute for Demographic Research. We are grateful for financial support from Netspar. Alex Lau provided valuable research assistance. Computations were performed using facilities at the Oxford Supercomputing Centre.

${ }^{\dagger}$ Frankfurt University and DIW Berlin, phaan@diw.de

${ }^{\ddagger}$ Department of Economics, Cornell University, vlprowse@gmail.com 


\section{Introduction}

Over the last several decades the longevity of individuals living in the developed world has improved considerably and consistently, and this trend looks set to continue. ${ }^{1}$ Such a demographic change poses numerous social and economic challenges. Notably, many public pension systems, which are typically compulsory defined benefit schemes, are being strained by the greater pension demands concurrent higher life expectancy. In response to this problem, an important political debate has arisen concerning how to reform public pension systems in order to address the fiscal demands being created by improving longevity. This debate has focused on identifying effective ways of increasing the age-based eligibility requirements associated with public pension benefits. The policy response thus far has reflected this theme: for example, Germany and the US have recently announced plans to gradually increase the full pensionable age, that is the age from which an individual may claim a non-reduced public pension, from 65 to 67 years.

In this paper, we contribute to the policy debate on how public pension systems can be reformed in order to deal effectively with the consequences for Government finances of increasing life expectancy. This is accomplished by specifying and estimating a comprehensive dynamic structural life-cycle model of employment, retirement and consumption. In our model an individual's optimal behavior depends, inter alia, on life expectancy and the design of the public pension system. Given the rules that describe optimal behavior, we determine empirically the behavioral and fiscal effects of an increase in life expectancy. Further, drawing on the estimated model, we explore the consequences of reductions in the generosity of the public pension system. In particular, we calculate the increase in the full pensionable age required to offset the implications for Government finances of a given increase in life expectancy. Second, and as an alternative solution to the fiscal problems created by improved longevity, we calculate the cut in the per-year value of public pension benefits which counteracts the fiscal consequences for the Government of the same increase in life expectancy. We compare these two revenue-equivalent policies and find that the increase in the full pensionable age elicits a larger response in individuals' employment and retirement behavior, and generates substantially higher expected total life-time consumption, than does the cut in the per-year value of public pension benefits.

The structural life-cycle model implemented herein is formulated to capture the primary intertemporal incentives that drive the effects of life expectancy and the public pension system on individuals' employment, retirement and consumption decisions. In particular, our model contains a realistic compulsory public pension system which provides retired individuals with a pension that reflects life-cycle employment and earnings outcomes. We follow, inter alios, De Nardi et al. (2010), van der Klaauw and Wolpin (2008) and Rust and Phelan (1997) by allowing an individual's life-cycle utility to be a function of heterogeneous individual-specific life expectancy. Moreover, extending on previous studies, life expectancy in our model is cohortspecific and therefore we capture the sizable improvements in life expectancy that have occurred in recent years. Additional features of the model include opportunities for retirement prior to the full pensionable age, detailed specifications of the tax and transfer systems, stochastic job offers, involuntary separations, saving opportunities and borrowing constraints.

\footnotetext{
${ }^{1}$ Oeppen and Vaupel (2002), for example, show that over the last 150 years life expectancy at birth in the developed world has been increasing at a rate of 2.5 years per decade. The authors further argue that this linear trend is likely to continue.
} 
Several previous studies have used structural life-cycle models to investigate the effects of public pension systems on labor supply, retirement and consumption decisions (see, for example, Casanova, 2010; French, 2005; French and Jones, forthcoming; Gustman and Steinmeier, 1986, 2005; Heyma, 2004; Jiménez-Martín and Sanchez Martín, 2007; Rust and Phelan, 1997; van der Klaauw and Wolpin, 2008). These studies typically find that the estimated preference parameters imply a strong dependence of optimal retirement decisions on the institutional rules that define the generosity of public pension benefits. Additionally, a largely separate literature presents empirical evidence of a direct effect of pension rights on retirement decisions. For example, Blau (1994), Blundell et al. (2002), Disney and Smith (2002), French and Jones (2010), Friedberg (2000) and Friedberg and Webb (2005) report micro-level evidence of a link between pension rights and the timing of retirement, while Blöndal and Scarpetta (1997) and Gruber and Wise (1998) demonstrate a similar relationship at the macro level. ${ }^{2}$ Much of the previous research in this area has drawn on concerns arising from increasing life expectancy to provide motivation, however, the focus of the analysis itself has been on understanding the behavioral effects of the incentives created by public pension systems. A direct link from life expectancy to individual behavior has therefore been absent. In contrast, this study examines the interplay between life expectancy, life-cycle employment, retirement and consumption behavior, and the incentives provided by the public pension system. The breadth of our analysis allows us to move beyond the previous literature and to address key public pension policy issues concerning the effectiveness of alterations in the design of public pension systems intended to alleviate the consequences for Governments' finances of increasing life expectancy.

Meanwhile, life-cycle modeling has been used to understand the implications of life expectancy for critically important yet relatively narrow aspects of behavior, specifically decisions related to savings and bequests. Notably, De Nardi et al. (2010) analyze the effect of life expectancy on the optimal savings decisions of retired individuals and show that an increase in life expectancy, ceteris paribus, drives individuals to raise asset holdings. Similarly, Gan et al. (2004) show that savings behavior is consistent with individuals' subjective beliefs about life expectancy and Hurd (1989) shows that consumption behavior is sensitive to the mortality rate. Finally, Brown (2001) demonstrates that individuals account for life expectancy when deciding whether to annuitize retirement resources. In order to tackle the policy questions central to this paper, we extend the application of structural life-cycle modeling by using such a framework to determine the effect of life expectancy on individuals' optimal employment and retirement behavior as well as on consumption, and therefore savings, decisions.

We choose to implement our model in the context of Germany. As described by BörschSupan and Schnabel (1998), Germany provides a leading example of a traditional welfare state, with relatively generous out-of-work transfers, high rates of taxation of earned income and a substantial compulsory pay-as-you-go public pension system; it is in such a context that issues surrounding the sustainability of public pension systems tend to be most pressing. Further, couching the analysis in the context of Germany allows us to exploit a unique pattern of variation in the evolution of demographic group-specific life expectancy which arose due to events that followed German reunification in 1990. Specifically, drawing on variation between demographic groups in the extent of improvements in life expectancy, we are able to demonstrate that our

\footnotetext{
${ }^{2}$ Extensive surveys of this literature are provided by Gruber and Wise (2004) and Gruber and Wise (2007).
} 
model, together with the estimated parameters, predicts the observed relationship between life expectancy and individuals' retirement decisions. This result suggests that our model provides a sound basis for subsequent counterfactual policy simulations which seek to determine the effects of improvements in life expectancy on individuals' optimal employment, retirement and consumption decisions.

In terms of data sources, we obtain information on life expectancy from the Human Mortality Database for Germany, which includes projections of age-specific life expectancies by cohort, region and gender. This data on life expectancy is combined with a sample of older individuals taken from the German Socio-Economic Panel and covering the years 1991 - 2007 inclusive. We estimate the parameters of our model, including preference parameters, parameters appearing in the job offer and involuntary separation probabilities, and parameters describing the wage offer distribution, using the Method of Simulated Moments as in Gourinchas and Parker (2002), French (2005) and French and Jones (forthcoming). In addition to replicating the observed relationship between life expectancy and retirement behavior as discussed in the previous paragraph, the fitted model is able to reproduce further features of our sample including the distribution of observed wages, the age profile of wealth and the age-specific rates of transitions from employment to unemployment and vice versa.

We draw on the estimated model and perform several counterfactual policy simulations, focusing on the case of Germany. We show that, holding fixed the tax, transfer and pension systems, the 6.4 year increase in age 65 life expectancy anticipated to occur over the 40 years that separate the 1942 and 1982 birth cohorts leads individuals approaching the full pensionable age of 65 years to postpone retirement, increase employment and increase wealth holdings. Further, this improvement in longevity causes average net Government revenue received from individuals aged less than the full pensionable age to increase; however, due to higher public pension demands, the Government's overall fiscal position is worsened substantially. Specifically, the increase in life expectancy under consideration leads average net Government revenue per person, summed over the life-cycle starting at age 40 years and continuing until death, to decrease by approximately 75000 Euros. We calculate that the full pensionable age must be increased by 4.34 years, from 65 years to 69.34 years, in order to restore the net position of the Government's budget. This policy change leads the average age of retirement to increase by approximately 4 years and causes average years of employment prior to retirement to increase by almost as much. Alternatively, the net position of the Government's budget can be reinstated via a cut of $37.7 \%$ in the per-year value of public pension benefits. Our results show that such a cut in the per-year value of public pension benefits has little impact on employment or retirement behavior; in consequence, expected total per-person post age 40 years consumption is over 100000 Euros higher if instead the fiscal consequences for the Government of 40 years worth of improvements in longevity are counteracted via an increase in the full pensionable age.

This paper proceeds as follows. Section 2 outlines our life-cycle model. Section 3 describes our data sources. Section 4 provides an overview of the adopted Method of Simulated Moments estimation methodology and presents our structural parameter estimates. Counterfactual policy analysis is contained in Section 5. Finally, Section 6 concludes. 


\section{Model}

\subsection{Overview}

Herein, we develop a dynamic structural model of individuals' employment, retirement and consumption behavior over the life-cycle. We propose a discrete-time finite-horizon model in which employment, retirement and consumption decisions are made at quarterly, i.e., three monthly, intervals. Individuals in employment are assumed to work full-time and this state is denoted by $f .{ }^{3}$ Similarly, we use $u$ and $r$ to denote unemployment and retirement respectively. Individuals are indexed by $i=1, \ldots, N$, and age, measured in quarters of a year, is indexed by $t .^{4}$ The maximum possible age to which an individual can live is denoted by $\bar{T}{ }^{5}$ We formulate our model such that it describes accurately the incentives facing individuals aged 40 years and over who reside in single-adult households and who do not have dependent children. ${ }^{6}$ Henceforth, the households under study are referred to as single-person households. Our sample selection criteria, explained below in Section 3.1, ensure that we rely on observations from this demographic group when estimating the parameters of the model. The older non-retired individuals under study form a vital demographic group for understanding the implications of public pension reforms. Indeed, previous work has shown that the labor supply and retirement decisions of older, yet working age, individuals are relatively elastic with respect to income (for example, Gruber and Wise, 2004; Haveman et al., 1991; Lalive et al., 2006). These findings suggest that the effects of alterations in the generosity of the public pension system will depend predominantly on the behavioral responses of older non-retired individuals. ${ }^{7}$

Each period, an individual enjoys a flow of utility which depends on current consumption, $c_{i, t}$, current leisure and individual-specific preference shifters. We use $U_{i, t}\left(c_{i, t}, f\right)$ to denote individual $i$ 's age $t$ flow utility if he or she is employed. Similarly, the flow utilities associated with unemployment and retirement are given by $U_{i, t}\left(c_{i, t}, u\right)$ and $U_{i, t}\left(c_{i, t}, r\right)$ respectively. The flow utilities take the following constant relative risk aversion (CRRA) specification

$$
U_{i, t}\left(c_{i, t}, j\right)=\beta G\left(c_{i, t}-c_{i, t} \eta_{i} 1[j=f]\right)+\varepsilon_{i, j, t} \text { for } j=f, u, r
$$

where $G(x)=\frac{x^{1-\rho}}{1-\rho}$. In (1), $\eta_{i} \in[0,1)$ describes the degree of complementarity between consumption and leisure. Specifically, $\eta_{i}$ is equal to the share of consumption necessary to compensate individual $i$ for the disutility of working. We allow heterogeneity in the degree of complementarity between leisure and consumption by assuming that $\eta_{i} \mid \chi_{i} \sim N\left(\mu_{\eta}, \sigma_{\eta}^{2}\right)$, where $\chi_{i}$ denotes the

\footnotetext{
${ }^{3}$ Given our sample selection criteria, explained below in Section 3.1, only approximately $5 \%$ of the population under study worked fewer than 30 hours per week and therefore it is reasonable to treat all employment as full-time work.

${ }^{4}$ To improve readability we do not introduce further subscripts to index specific cohorts or years: cohort information is specific to the individual, and together with age information, the year is thereby defined.

${ }^{5}$ We follow the life tables and take $\bar{T}$ to be 110 years.

${ }^{6}$ We assume that family composition does not change in the future. However, our model is fully applicable to individuals who have experienced alternative household compositions, specifically martial status and dependent children, before entering the sample. Appendix D explains how this is achieved.

${ }^{7}$ We refrain from extending our analysis to younger households or to multi-adult households as, in both cases, the incentives created by the tax, transfer and pensions systems are far more complex. Any model of such household groups is therefore likely to be less exact. Based on a similar justification, De Nardi et al. (2010) also focus on single-person households.
} 
individual's observed characteristics at the time of labor market entry. In order to guarantee that $\eta_{i} \in[0,1)$ we truncate $\eta_{i}$ from above at 0.999 and from below at zero. The parameter $\rho$ represents the coefficient of relative risk aversion and may take any weakly positive value except unity. In our specification, $\rho=0$ corresponds to risk neutrality and strictly positive values of $\rho$ imply risk aversion. The unobservables $\varepsilon_{i, f, t}, \varepsilon_{i, u, t}$ and $\varepsilon_{i, r, t}$ represent transient individualspecific preference shifters while the parameter $\beta$ determines the importance of consumption and leisure in preferences, relative to the transient individual-specific unobservables. ${ }^{8}$

Current consumption is the sum of current net income and current dissaving. Current net income, in turn, depends on the individual's gross incomes from employment and from interest on wealth, and on the contemporaneous tax, transfer and pension systems. The public pension system determines the value of any pension income that a retired individual receives from the State as well as the rules concerning eligibility to receive public pension benefits. The tax system determines the extent of any deductions from gross income, including income tax payments and Social Security Contributions. The transfer system, meanwhile, controls the generosity of outof-work transfers. Our model includes the two leading forms of out-of-work transfers, namely, Social Assistance and Unemployment Insurance.

Individuals are forward-looking and each period make employment, retirement and consumption decisions in order to maximize the discounted expected value of future utility. Retirement is treated as an absorbing state; a retired individual cannot make a transition into employment or unemployment..$^{9}$ Formally, individual $i$ 's age $t$ optimization problem can be written as follows

$$
\max _{d, c} E_{t} \sum_{s=t}^{\bar{T}} \delta^{s-t} k_{i, s, t} U_{i, s}\left(c_{i, s}, d_{i, s}\right) .
$$

In the above $d_{i, t} \in\{f, u, r\}$ is a categorial variable which codes the individual's age $t$ labor supply and retirement behavior. The variable $d$ details the individual's employment and retirement behavior in each remaining period of the individual's life. Similarly, $c$ denotes the individual's consumption choice in each remaining period of the individual's life. The operator $E_{t}$ is an expectation conditional on the individual's age $t$ information set. In this set-up, payoffs occurring in the future are discounted due to: (i) subjective time discounting; and (ii) mortality risk. The variable $\delta \in[0,1]$ denotes the individual's subjective time discount factor. Meanwhile, $k_{i, s, t}$ is the probability of the individual surviving until age $s$ conditional on being aged $t$.

The collection of individual-specific survival rates over the whole life-cycle, $\left\{k_{i, t+0.25, t}\right\}_{t=1}^{\bar{T}-0.25}$, defines the individual's life expectancy at each age. The inclusion of the individual-specific survival probabilities in the individual's objective function therefore reflects the dependence of the individual's life-cycle utility on life expectancy. We follow, inter alios, De Nardi et al. (2010), van der Klaauw and Wolpin (2008) and Rust and Phelan (1997) and allow heterogeneity in life expectancy. Specifically, we allow variation in survival rates, and therefore life expectancy, according to gender and region of residence. Further, and in addition to the related literature, we

\footnotetext{
${ }^{8}$ The $\varepsilon$ s are assumed to occur independently over individuals. The $\varepsilon$ s for individual $i$ are assumed to occur independently over time and over the labor market states $j=f, u, r$. Further, the individual's age $t \varepsilon$ s are assumed to be independent of the individual's age $t$ observed characteristics. Additionally, $\varepsilon_{i, j, t}$ for all $i, j$ and $t$ is assumed to have a type I extreme value distribution. The inclusion of this form of unobservable in the flow utilities has the effect of smoothing the value function and thus facilitates estimation of the structural parameters.

${ }^{9}$ This assumption is in line with the German legislation and is strongly supported by the data.
} 
allow for improvements in life expectancy over cohorts. Section 3.2 below discusses the empirical relevance and statistical advantages associated with our relatively rich approach to modeling life expectancy. The optimization process is subject to an intertemporal budget constraint. In addition, behavior is subject to constraints on borrowing and on the availability of employment opportunities.

In this setting, forward-looking optimizing behavior on the part of the individual implies that employment and consumption decisions prior to retirement, as well as the timing of retirement itself, depend, inter alia, on life expectancy and the public pension system. Below we discuss our life-cycle model in more detail. We describe in turn: (i) the processes that determine job offers and involuntary separations and thereby dictate employment opportunities; (ii) the composition of gross wage income; (iii) the per-period net income arising from each of employment, unemployment and retirement; (iv) borrowing constraints, consumption possibilities and the intertemporal budget constraint; and (v) the optimal arrangement of employment, retirement and consumption over the life-cycle.

\subsection{Employment Opportunities}

An individual's behavior is constrained by the availability of employment opportunities. We model such constraints as follows. Each period an individual who was unemployed in the previous period receives a job offer with probability $\Theta_{i, t}$. Upon receiving a job offer, the individual observes the current gross wage, $w_{i, t}$, associated with the job opportunity. The age $t$ job offer probability takes the form

$$
\Theta_{i, t}=\Phi\left(\lambda_{\Theta} x_{i, t}+\mu_{i}^{\Theta}\right) .
$$

Here and henceforth $\Phi()$ denotes the cumulative distribution function of a standard normal random variable. We allow the job offer probability to depend on age, region of residence and health status, and variables measuring these characteristics are included in $x_{i, t} . \lambda_{\Theta}$ is a suitably dimensioned parameter vector. Finally, $\mu_{i}^{\Theta}$ represents unobserved individual characteristics that impact on the job offer probability. Further details concerning $\mu_{i}^{\Theta}$ are provided at the end of this subsection. An individual in receipt of a job offer has the option of moving into employment in the current period. With probability $\left(1-\Theta_{i, t}\right)$ a previously unemployed individual does not receive a job offer at age $t$. In such a case a transition into employment is impossible in the current period.

Similarly, each period an individual who was employed in the previous period experiences an involuntary separation with probability $\Gamma_{i, t}$. The age $t$ probability of an involuntary separation takes the form

$$
\Gamma_{i, t}=\Phi\left(\lambda_{\Gamma} x_{i, t}+\mu_{i}^{\Gamma}\right),
$$

where $\lambda_{\Gamma}$ is a suitably dimensioned parameter vector and $\mu_{i}^{\Gamma}$ is an unobserved individual effect which we describe at the end of this subsection. An individual subject to an involuntary separation does not have the option of remaining in employment in the current period. With probability $\left(1-\Gamma_{i, t}\right)$ a previously employed individual does not experience an involuntary separation and thus has the opportunity to stay in employment in the current period. Such an individual receives a new gross wage offer of $w_{i, t}$. 
The unobserved individual effects appearing in the job offer and involuntary separation probabilities are interpreted as permanent unobserved individual characteristics that impact on an individual's ability to find or keep a job. These unobservables are assumed to be assigned to an individual when he or she first enters the labor market. Further, we posit the following joint distribution for the unobserved individual effects that appear in the job offer and involuntary separation probabilities: $\left[\mu_{i}^{\Theta}, \mu_{i}^{\Gamma}\right] \mid \chi_{i} \sim N\left(0, \Sigma^{\mu}\right)$ where, as above, $\chi_{i}$ denotes the individual's observed characteristics at the time of labor market entry.

\subsection{Gross Wage Income}

For an individual who accepts employment, current period gross wage income takes the form of the gross hourly wage associated the current job offer, $w_{i, t}$, multiplied by usual hours of work. ${ }^{10}$ As gross wage income provides the basis for most components of current and future financial incentives we adopt a rich specification of gross wages. Specifically, individual $i$ 's $\log$ gross offered wage is assumed to be composed as follows

$$
\log \left(w_{i, t}\right)=\lambda z_{i, t}+\alpha_{i}+\tau_{i, t}+v_{i, t}
$$

In the above $z_{i, t}$ are observed individual characteristics that affect wages including education, region of residence and experience, and $\lambda$ is a suitably dimensioned parameter vector. The inclusion of experience is important here because it captures the endogenous accumulation of experience-based human capital as in, for example, Eckstein and Wolpin (1989). The final three terms in the wage equation are the unobserved components of wages: $\alpha_{i}$ is a permanent individual-specific random effect, representing ability or skills; $\tau_{i, t}$ is a persistent unobservable, which we interpret as an employer-employee match-specific productivity effect; and $v_{i, t}$ is a transitory wage shock.

We now outline the assumed distributions of each of the three unobserved components of gross offered wages. The permanent unobservable $\alpha_{i}$ is assigned to an individual when he or she first enters the labor market. We assume $\alpha_{i} \mid \chi_{i} \sim N\left(0, \sigma_{\alpha}^{2}\right)$. The persistent unobservable $\tau_{i, t}$, representing match-specific productivity, evolves as follows. For an individual who was employed in the previous period, $\tau_{i, t}$ keeps the same value as in the previous period with probability $\Pi$. However, with probability $(1-\Pi)$ a previously employed individual's match-specific productivity is subject to a shock. In such a case, the individual receives a new match-specific productive effect drawn from the following distribution: $\tau_{i, t} \mid \varphi_{i, t} \sim N\left(0, \sigma_{\tau}^{2}\right)$ where $\varphi_{i, t}$ denotes the individual's age $t$ characteristics, including previous labor market outcomes and previous unobserved characteristics. We thus interpret $\Pi$ as the probability of an employed individual's match-specific component of productivity persisting into the next period. An individual who was unemployed in the previous period and who is in receipt of a job offer in the current period also receives a new match-specific productivity shock distributed as follows: $\tau_{i, t} \mid \varphi_{i, t} \sim N\left(0, \sigma_{\tau}^{2}\right){ }^{11}$

\footnotetext{
${ }^{10}$ We assume that employment takes the form of 39 hours of work per week. This corresponds to the average weekly hours of work of the employed individuals in our sample.

${ }^{11}$ We note that, in contrast to Low et al. (2010), we do not model, or attempt to observe, transitions between employers. Therefore, we identify the parameters $\Pi$ and $\sigma_{\tau}^{2}$ purely from individual-specific wage observations.
} 
Finally, concerning the transitory wage shock, we assume $v_{i, t} \mid \varphi_{i, t} \sim N\left(0, \sigma_{v}^{2}\right){ }^{12}$

\subsection{Net Income}

We now describe how the tax, transfer and pension systems combine with an individual's labor market status to determine the individual's net income. We restrict our discussion to those institutional features that impact on the financial incentives facing members of the demographic group under study, specifically older working-age individuals residing in single-person households. As justified previously, our analysis focuses on Germany. Immediately below we indicate how our model captures the German institutional environment. Appendix A, meanwhile, provides further details concerning the German tax, transfer and pension systems in the years covered by our sample, that is $1991-2007 .{ }^{13}$

\subsubsection{Net Income if Employed}

An employed individual receives a gross income equal to the total value of gross wage income, as described above in Section 2.3, and interest income from wealth, with the latter being equal to the real interest rate times the value of the individual's stock of wealth. ${ }^{14}$ The net income received by an employed individual aged $t, m_{i, f, t}$, is computed by applying to gross income the appropriate deductions for Social Security Contributions and income tax.

Social Security Contributions are made for health, pension and Unemployment Insurance benefits and are obligatory. Social Security Contributions are payable at a constant rate on all gross wage income above a disregard and below an earnings cap. Social Security Contributions are not payable on any gross wage income in excess of the earnings cap. In addition to the employee's Social Security Contributions, the employer pays the same amount in Social Security Contributions. ${ }^{15}$ Income tax is payable on the entirety of an individual's taxable income. Taxable income, in turn, consists of any gross income in excess of the sum of the universal tax-free allowance and permissable Social Security Contributions. ${ }^{16}$ Income tax is payable at a rate that is increasing in the individual's taxable income. ${ }^{17}$

\footnotetext{
${ }^{12}$ Additionally, at all ages, the three unobserved components of wages are assumed to be mutually independent and independent of the unobservables $\left[\mu_{i}^{\Theta}, \mu_{i}^{\Gamma}\right]$ that affect the job offer and involuntary separation probabilities.

${ }^{13}$ During the sample period, the German tax, transfer and pension systems were subject to several reforms. We take current net income to be a function of the contemporaneous tax, transfer and pension systems. We therefore account for the effects of tax, transfer and pension reforms on static current-period incentives. We assume that individuals expect that the current tax and transfer systems will persist into future years. This assumption is plausible as either the reforms to the tax and transfer systems that occurred during the sample period were announced at short notice or the time schedule for their implementation was highly uncertain. We also assume that individuals expect that the cohort-specific rules which define the public pension system will be maintained indefinitely. In Appendix A.2.4 we argue that the nature of the public pension reforms that occurred during the sample period was such that this assumption is realistic.

${ }^{14}$ Our analysis follows French and Jones (forthcoming) and assumes an annualized real interest rate of $3 \%$.

${ }^{15}$ Since July 2005 there has been a small divergence from this rule which we neglect in this study.

${ }^{16}$ The value of Social Security Contributions that can be set against gross income when computing taxable income is subject to a maximum limit.

${ }^{17}$ We note here two further features of income tax that apply irrespective of an individual's labor market status. First, only interest income from wealth in excess of a disregard counts towards taxable income. Second, there exists a Solidarity tax which was introduced in order to finance the cost of German reunification. The Solidarity tax is proportional to an individual's income tax liability. Currently, there is no indication that the Solidarity tax will be phased out.
} 


\subsubsection{Net Income if Unemployed}

An unemployed individual receives a gross income equal to the value of interest income from wealth. The net income received by an unemployed individual aged $t, m_{i, u, t}$, is computed by adding to gross income any transfer payments from the Government and applying the appropriate deduction for income tax. Government-provided transfers to unemployed individuals take two forms: Means-tested Social Assistance benefits which ensure a universal minimum income, irrespective of the individual's employment or earnings history; and Unemployment Insurance benefits which provide an unemployed individual with a fraction of his or her previous net earnings. Social Assistance benefits are paid indefinitely while Unemployment Insurance benefits are paid for an entitlement period which is determined by an individual's age and recent employment history. Social Assistance benefits have no tax implications. Unemployment Insurance benefits are not directly taxed. Instead, Unemployment Insurance benefits are added to interest income and the individual's average tax rate is determined based on the same tax schedule as applicable to employed individuals (see Section 2.4.1). The individual's tax liability is determined by applying the individual-specific average tax rate to interest income.

\subsubsection{Net Income if Retired}

A retired individual receives a gross income equal to the value of public pension benefits plus any interest income from wealth. The net income of a retired individual aged $t, m_{i, r, t}$, is equal to gross income less income tax and plus any Government-mandated transfers. The sum of interest income from wealth and $30 \%$ of public pension benefits, less the tax-free allowance, is subject to income tax. ${ }^{18}$ Given taxable income, a retired individual's income tax liability is calculated using the same formula as applicable to employed individuals (see Section 2.4.1). Pensioners are eligible to receive a non-taxable means-tested transfer similar in generosity to Social Assistance. ${ }^{19}$

In the current setting, public pension benefits provide a major source of income for retired individuals. $^{20}$ We embed within our model the most important aspects of the German public pension system. In this subsection, we provide an overview of the relevant institutional rules. In line with many public pension systems, German public pension benefits reflect an individual's employment and earnings outcomes at all ages prior to retirement. Specifically, public pension benefits are linked to an individual's labor market history via a quantity we refer to as "weighted pension points". An individual accumulates one pension point for every year of employment and

\footnotetext{
${ }^{18}$ Until the year 2004, approximately $30 \%$ of public pension income was subject to income tax. Following a reform in 2004, Social Security Contributions for public pension benefits have been subject to gradually increasing taxation, while public pension benefits have seen a corresponding increase in tax exemption. It is anticipated that by 2040 all public pension income will be tax exempt. The design of this reform is such that life-cycle income is not systematically affected. Therefore, in our modeling, we reasonably assume throughout that $30 \%$ of public pension income is subject to income tax.

${ }^{19}$ The exact form of this transfer has varied over the years but has never differed substantially from Social Assistance.

${ }^{20}$ Börsch-Supan and Wilke (2004) note that the first pillar pension system, or public pension system, in Germany accounts for approximately $85 \%$ of total pension income. Individual and occupational pensions, meanwhile, account for $10 \%$ and $5 \%$ of pension income respectively. Given the relatively small share of pension income provided by individual and occupational pensions, we refrain from explicitly modeling these schemes. Instead, we assume that the provision for private saving afforded by our model (see Section 2.5) approximates the saving opportunities offered by individual and occupational pension plans.
} 
such pension points attract a weight of $\min \left\{w_{i, t} / \bar{w}_{i, t}, \operatorname{Max}_{i, t}\right\}$, where $\bar{w}_{i, t}$ denotes the mean gross wage in the period when individual $i$ is age $t$ and $\operatorname{Max}_{i, t}$ denotes the year-specific cap on pension point weights. During the sample period, the cap on pension point weights varied slightly but was roughly equal to two in all years. ${ }^{21}$ Consequently, for an employed individual earning less than approximately double the current mean gross wage, pension points are weighted by the ratio of the individual's current gross wage to the current mean gross wage, while individuals earning more than approximately double the current mean gross wage are allocated a pension point weight of roughly two. An individual also accumulates one pension point for every year of Unemployment Insurance eligible unemployment. ${ }^{22}$ Such pension points are allocated a weight of $\min \left\{0.8 \times w_{i, t^{\prime}} / \bar{w}_{i, t}, 0.8 \times \operatorname{Max}_{i, t}\right\}$, where $t^{\prime}$ denotes the age at which the individual was last employed. Thus, up to a cap of roughly 1.6, an unemployed individual's pension points are weighed by the ratio of $80 \%$ of the individual's most recent gross wage relative to the current mean gross wage. ${ }^{23}$

The full pensionable age applicable to the individuals under study is 65 years. $^{24}$ At this age, an individual can retire and receive a publicly provided pension with a value proportional to the sum of the individual's weighted pension points accumulated prior to age 65 years. The proportionality factor is a year-specific figure that differs between east and west Germany (see Appendix A.2.1). The German public pension system is relatively generous. Specifically, according to Börsch-Supan and Schnabel (1998), in 1998 public pension benefits provided a replacement rate of around $70 \%$ of pre-retirement net earnings for an individual retiring at the full pensionable age with 45 years of working experience and average life-time earnings.

The German public pension system provides numerous opportunities for individuals to enter retirement prior to the full pensionable age and our model captures most important routes into early retirement. Specifically, our model recognizes that an individual may be eligible for retirement prior to the full pensionable age on the grounds of: (i) gender, specifically being a woman; (ii) disability; or (iii) working history, specifically having previously worked at least 35 years. It should be noted that eligibility for early retirement on the grounds of gender or working history depends on the individual's age; for example, those who have worked at least 35 years may retire only from age 63 years. The age, gender and working history based eligibility criteria for retirement prior to the full pensionable age are entirely objective and we hard-code the relevant rules into our model. When doing this, we account fully for variation over time in the eligibility criteria for early retirement. See Appendix A.2.3 for a description of the early retirement eligibility criteria.

In contrast, the rules that determine eligibility for public pension benefits on the grounds of disability are complex and the operationalization of these rules has inevitably been somewhat

\footnotetext{
${ }^{21}$ Before the computation of the weight attached to an individual's pension points, the wages of east Germans are subject to an adjustment. Appendix A.2.1 provides further details.

${ }^{22}$ Prior to 2006, unemployed individuals who were ineligible for Unemployment Insurance accumulated pension points which received a very small weight, specifically, 0.0834. Since 2006, unemployed individuals who are ineligible for Unemployment Insurance have been unable to accumulate pension points.

${ }^{23}$ Appendix A.2.2 discusses further routes by which individuals can accumulate pension points.

${ }^{24}$ In fact, this is a minor simplification. In 2007, the last year covered by our sample, the German parliament voted to increase gradually the full pensionable age to 67 years for individuals born after 1963 . This reform affected just a handful of the (relatively young) individuals in our sample, and only in the second half of 2007. Thus, in our analysis we assume a full pensionable age of 65 years for all sample members.
} 
subjective. For the purpose of implementing our model, we assume that individual $i$ has a probability $\Upsilon_{i, t}$ of being eligible, due to disability, for early retirement. The age $t$ probability of being eligible for public pension benefits on the grounds of disability is as follows

$$
\Upsilon_{i, t}=\Phi\left(\lambda_{\Upsilon} q_{i, t}\right)
$$

where $q_{i, t}$ contains variables that measure the individual's gender and health status, and $\lambda_{\Upsilon}$ is a suitably dimensioned parameter vector.

Individuals who retire before the full pensionable age may receive a "non-reduced public pension", the value of which is obtained by multiplying the individual's weighted pension points accumulated at the time of retirement by the same proportionality factor as used to determine the value of public pension benefits for individuals retiring at the full pensionable age. Alternatively, depending on the year-specific rules and on gender, disability status, working history and age, an individual's public pension benefits may be subject to adjustments. Appendix A.2.3 details the rules that determine the nature of any adjustments to the value of the public pension benefits received by early retirees.

\subsection{Borrowing, Consumption and the Intertemporal Budget Constraint}

The value of the stock of individual $i$ 's wealth at age $t$ is denoted by $W_{i, t}$. Here and henceforth, wealth is taken to refer to an individual's private wealth holdings, and therefore excludes the value of any entitlements to the public pension or other social programs. The individual faces borrowing constraints which restrict wealth to being non-negative and therefore we have

$$
W_{i, t} \geq 0 \text {. }
$$

This assumption, which follows French (2005) and Low et al. (2010), reflects that borrowing typically requires collateral and that individuals are unable to borrow against future earnings or future Unemployment Insurance, Social Assistance or public pension benefits. Subject to the above-described borrowing constraint, each period, a non-retired individual chooses a consumption level, $c_{i, t}$. Thus, we have the following intertemporal budget constraint which describes quarter-by-quarter wealth accumulation for a non-retired individual

$$
W_{i, t+0.25}=W_{i, t}+1\left(d_{i, t}=f\right) m_{i, f, t}+1\left(d_{i, t}=u\right) m_{i, u, t}-c_{i, t} .
$$

Note that, given consumption behavior, wealth accumulation depends on the real interest as the net incomes $m_{i, f, t}$ and $m_{i, u, t}$ include the net of tax value of any interest income from wealth. ${ }^{25}$

We assume that a retired individual consumes out of accumulated wealth at a level consistent with the actuarially fair annuity value of his or her stock of wealth at the date of retirement. The per-period consumption enjoyed by an individual who retires at age $t$ thus given by

$$
c_{i, t}=m_{i, r, t}+a_{i, t},
$$

\footnotetext{
${ }^{25}$ In contrast to the models of retirement behavior developed by, for example, French and Jones (forthcoming) and Rust and Phelan (1997), we do not include medical expenses. This is reasonable given that we implement the model in the context of Germany, which has a universal health care system.
} 
where $a_{i, t}$ denotes per-period annuity value of wealth for an individual who retires at age $t$. This modeling assumption greatly simplifies the complex process of consumption determination among the retired population. However, this specification captures the primary intertemporal incentives that are important for the current application. In particular, our modeling approach recognizes that: (i) wealth accumulation prior to retirement is valuable in retirement; (ii) the value of accumulated wealth is negatively related to life expectancy, as the actuarially fair annuity value of wealth depends negatively on life expectancy; and (iii) financing consumption out of accumulated wealth is a substitute for funding consumption from public pension benefits.

\subsection{Optimal Labor Supply, Retirement and Consumption}

Drawing on dynamic programming techniques, we use our model to describe an individual's optimal employment, retirement and consumption behavior over the life-cycle. An individual's age $t$ optimization problem can be expressed in terms of the state-specific value functions $V_{t}^{j}\left(c_{i, t}\right)$ for $j=f, u, r$, which define the maximized discounted expected value of the individual's future life-cycle utility conditional on currently being in state $j$ with consumption $c_{i, t}$. Using $\check{t}$ to denote the individual's age in the next quarter, i.e., $\check{t} \equiv t+0.25$, the state-specific value functions are defined recursively as follows

$$
\begin{aligned}
& V_{i, t}^{f}\left(c_{i, t}\right)=U_{i, t}\left(c_{i, t}, f\right)+\delta k_{i, \breve{t}, t} E_{t}\left[\Gamma_{i, \check{t}}\left\{\Lambda_{i, \check{t}} \max \left\{V_{i, \breve{t}}^{u}, V_{i, \breve{t}}^{r}\right\}+\left(1-\Lambda_{i, \check{t}}\right) V_{i, \breve{t}}^{u}\right\}+\right. \\
& \left.\left(1-\Gamma_{i, \check{t}}\right)\left\{\Lambda_{i, \check{t}} \max \left\{V_{i, \breve{t}}^{f}, V_{i, \breve{t}}^{u}, V_{i, \breve{t}}^{r}\right\}+\left(1-\Lambda_{i, \check{t}}\right) \max \left\{V_{i, \breve{t}}^{f}, V_{i, \check{t}}^{u}\right\}\right\}\right], \\
& V_{i, t}^{u}\left(c_{i, t}\right)=U_{i, t}\left(c_{i, t}, u\right)+\delta k_{i, \breve{t}, t} E_{t}\left[\left(1-\Theta_{i, \breve{t}}\right)\left\{\Lambda_{i, \breve{t}} \max \left\{V_{i, \breve{t}}^{u}, V_{i, \breve{t}}^{r}\right\}+\left(1-\Lambda_{i, \breve{t}}\right) V_{i, \breve{t}}^{u}\right\}+\right. \\
& \left.\Theta_{i, \breve{t}}\left\{\Lambda_{i, \breve{t}} \max \left\{V_{i, \breve{t}}^{f}, V_{i, \breve{t}}^{u}, V_{i, \breve{t}}^{r}\right\}+\left(1-\Lambda_{i, \breve{t}}\right) \max \left\{V_{i, \breve{t}}^{f}, V_{i, \breve{t}}^{u}\right\}\right\}\right] \text {, } \\
& V_{t}^{r}=U_{i, t}\left(c_{i, t}, r\right)+\delta k_{i, \check{t}, t} E_{t} V_{i, \check{t}}^{r}
\end{aligned}
$$

In (10)-(12) above, $\Lambda_{i, \check{t}}$ is the individual's probability of being eligible for retirement at age $\check{t}^{26}$ Meanwhile, $V_{i, \breve{t}}^{f}$ and $V_{i, \breve{t}}^{u}$ are defined as the age $\check{t}$ value functions associated with age $\check{t}$ employment and unemployment, respectively, after age $\check{t}$ consumption has been optimized. Specifically,

$$
V_{i, \breve{t}}^{j}=\max _{c_{i, \grave{t}}} V_{i, \breve{t}}^{j}\left(c_{i, \check{t}}\right) \text { for } j=f, u
$$

Subject to the above discussed constraints on the availability of employment opportunities and on wealth accumulation, each period, an individual is able to adjust his or her employment, retirement and consumption behavior. At age $t$, a forward-looking optimizing in-

\footnotetext{
${ }^{26}$ Following the discussion above in Section 2.4.3, an individual may be eligible for retirement at age $\check{t}$ either on the grounds of disability, an event which occurs with probability $\Upsilon_{i, \check{t}}$ as defined above in equation (6), or due to having satisfied the relevant age, gender and working history based criteria. Therefore, the probability of an age $\check{t}$ individual being eligible for retirement, $\Lambda_{i, \check{t}}$, takes the following form:

$$
\Lambda_{i, \check{t}}= \begin{cases}1 & \text { if age, gender and working history based criteria for retirement eligibility are satisfied; } \\ \Upsilon_{i, \check{t}} & \text { otherwise. }\end{cases}
$$
}

Finally, all individuals may retire at the full pensionable age of 65 years and therefore we have $\Lambda_{i, 65}=1$. 
dividual in possession of a job offer but not eligible for retirement will choose employment and a current-period consumption level of $c_{t, t}^{\prime}$ if and only if $V_{i, t}^{f}\left(c_{i, t}^{\prime}\right)>\max _{c_{i, t}, c_{i, t} \neq c_{i, t}^{\prime}} V_{i, t}^{f}\left(c_{i, t}\right)$ and $V_{i, t}^{f}\left(c_{i, t}^{\prime}\right)>\max _{c_{i, t}} V_{i, t}^{u}\left(c_{i, t}\right)$, and otherwise will choose to be unemployed and to consume $c_{i, t}=\max _{c_{i, t}} V_{i, t}^{u}\left(c_{i, t}\right)$. If such an individual instead is eligible for retirement then he or she will choose employment and a current-period consumption level of $c_{i, t}^{\prime}$ if, in addition to the previous two inequalities, it is also the case that $V_{i, t}^{f}\left(c_{i, t}^{\prime}\right)>V_{i, t}^{r}$. An individual who does not have a job offer and is not eligible early retirement will be unemployed with a current-period consumption level of $c_{i, t}=\max _{c_{i, t}} V_{i, t}^{u}\left(c_{i, t}\right)$. Alternatively, if this individual is eligible for retirement then he or she will choose unemployment with a current-period consumption level of $c_{i, t}^{\prime}$ if and only if $V_{i, t}^{u}\left(c_{i, t}^{\prime}\right)>\max _{c_{i, t}, c_{i, t} \neq c_{i, t}^{\prime}} V_{i, t}^{u}\left(c_{i, t}\right)$ and $V_{i, t}^{u}\left(c_{i, t}^{\prime}\right)>V_{i, t}^{r}$. Upon reaching the full pensionable age all remaining non-retired individuals must enter retirement.

In this setting there are several mechanisms linking an individual's current employment, retirement and consumption decisions with expected future payoffs. Focusing on those intertemporal linkages directly related to retirement, we note that employment in the current period adds to an individual's stock of pension points. Current employment therefore, ceteris paribus, increases income in the event of retirement. Current period unemployment has a similar albeit smaller effect, provided that the unemployed individual is receiving Unemployment Insurance benefits. Furthermore, working in the current period adds to the individual's experience which, assuming positive wage returns to experience, leads to higher expected future wage offers and, ceteris paribus, to higher public pension benefits in retirement. ${ }^{27}$ Finally, and perhaps most transparently, accumulation of wealth prior to retirement, ceteris paribus, allows an individual to increase income in retirement.

Life expectancy interacts with the above-described intertemporal dependencies. We discuss here two of the incentive effects created by an increase in life expectancy, reflected in our model by an appropriate adjustment of the individual-specific survival probabilities, $\left\{k_{i, t+0.25, t}\right\}_{t=1}^{\bar{T}-0.25}$. First, an increase in life expectancy increases the expected duration over which an individual will receive the publicly provided pension. In consequence, an increase in longevity, ceteris paribus, raises the expected future returns to the accumulation of pension points, and thus creates an incentive to postpone retirement. Second, an increase in life expectancy increases the time over which an individual may enjoy the returns from accumulated wealth. Ceteris paribus, the incentive to save is therefore increasing in life expectancy. However, the total effect of an increase in life expectancy on behavior over the life-cycle is, a priori, impossible to determine. Indeed, since savings and entitlements to public pension benefits are substitutes in terms of their effects on utility in retirement, individuals may rationally choose to respond to an increase in life expectancy by increasing employment and reducing wealth accumulation, or vice versa. Moreover, an increase in life expectancy may lead to higher saving or increased employment early in the life-cycle followed by earlier retirement. ${ }^{28}$

\footnotetext{
${ }^{27}$ Intertemporal linkages also occur through Unemployment Insurance benefits: employment increases the duration of entitlement to Unemployment Insurance in future periods, and wage based rewards arising from human capital accumulation mean that current employment leads to higher Unemployment Insurance benefits in the case of future unemployment. See Haan and Prowse (2010) for further discussion.

${ }^{28}$ Optimizing behavior over the life-cycle does, however, rule out an increase in life expectancy causing weakly lower saving and weakly higher unemployment early in the life-cycle followed by strictly earlier retirement.
} 


\section{Data Sources and Sample Selection}

In order to estimate the parameters of the above-described model we draw on data from the German Socio-Economic Panel and the Human Mortality Database.

\subsection{German Socio-Economic Panel (SOEP)}

The German Socio-Economic Panel (SOEP) is an annual, representative panel survey of over 11000 households in Germany. The SOEP contains information about socio-economic variables, including income and working behavior, at the individual and household levels. ${ }^{29}$ We use the annual SOEP surveys from the years 1992 - 2008 inclusive, which contain retrospective information covering the fiscal years $1991-2007 .^{30}$ Behavior is analyzed on a quarterly, i.e., 3 monthly, basis. ${ }^{31}$ We construct an unbalanced panel of individuals who: (i) are aged 40-65 years inclusive; (ii) are living in single-adult households; and (iii) do not have dependent children. ${ }^{32}$ Furthermore, we exclude individuals whose primary earnings are from self-employment as well as those in full-time education because, in both cases, labor supply behavior differs substantially from that of the rest of the population of interest. These exclusions yield a sample with 40409 person-quarter observations corresponding to 2389 different single individuals of whom 1302 are women and 1087 men. The median number of observations per individual is 11 quarters and around $25 \%$ of the individuals are observed for 5 or more years.

The SOEP data set contains detailed information about individuals' employment and retirement behavior in each month. We group the monthly information and form quarterly observations with an individual's labor market state in the first month of the quarter determining the quarterly outcome. We distinguish between employment, assumed to be full-time work, unemployment and retirement. Individuals who report sufficient income from pensions are classified as retired. A measure of experience at the time that the individual entered the sample is constructed from retrospective information concerning the individual's working history. This variable is then updated at quarterly intervals over the sample period in accordance with the individual's observed employment behavior. In line with the relevant legislation during the observation period, all remaining non-retired individuals are reclassified as retired at age 65 years.

Figure 1 shows the shares of employment, unemployment and retirement by age separately for men and women and by region of residence, i.e., east or west Germany, averaged over the observation period. In general, the behavior of the various subgroups is similar. Early retirement among individuals in their 40s or early to mid 50s is rare. However, early retirement is much more common for individuals in their late 50s and early 60s. Indeed, at age 60 years, $40 \%$ of individuals are in early retirement and more than $80 \%$ of individuals enter retirement before the full pensionable age of 65 years. Employment rates for men and women are quite similar. This is not surprising since our sample consists only of single-person households. However, as expected, we find large differences in employment and retirement behavior according to region of residence:

\footnotetext{
${ }^{29}$ Wagner et al. (2007) provide an overview of the SOEP.

${ }^{30}$ The German fiscal year commences on $1^{\text {st }}$ January.

${ }^{31}$ This level of disaggregation allows us to model accurately the Unemployment Insurance system.

${ }^{32}$ These sample selection criteria complement the structural model presented in Section 2.
} 
Figure 1: Employment, unemployment and retirement over the life-cycle by gender and region of residence

(a) Women

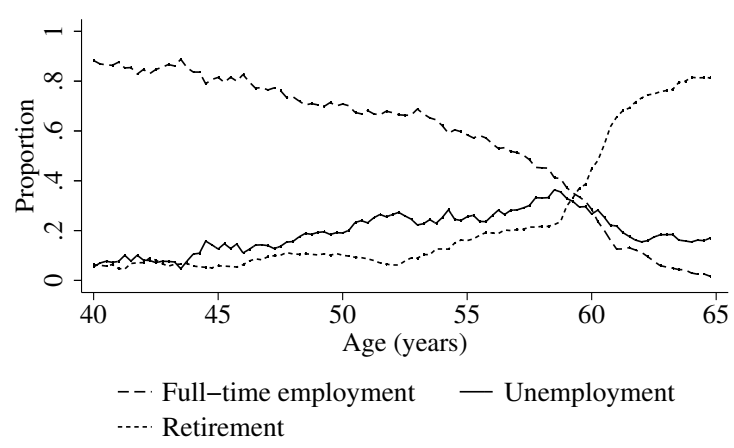

(c) West Germany

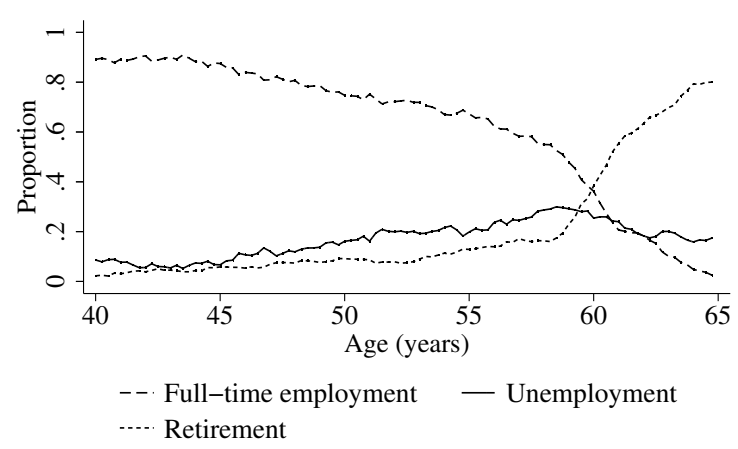

(b) Men

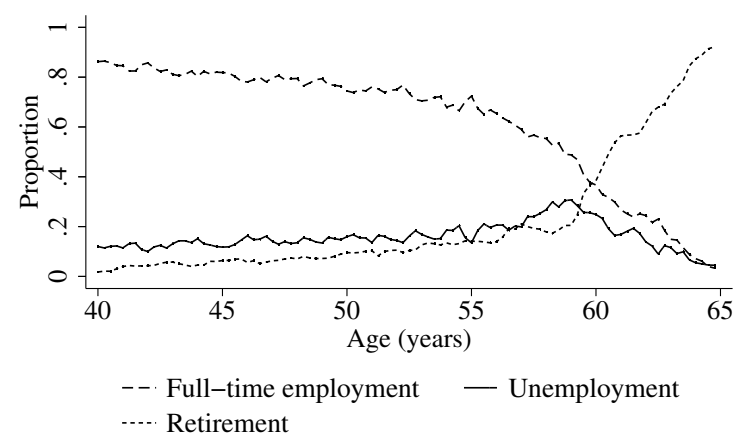

(d) East Germany

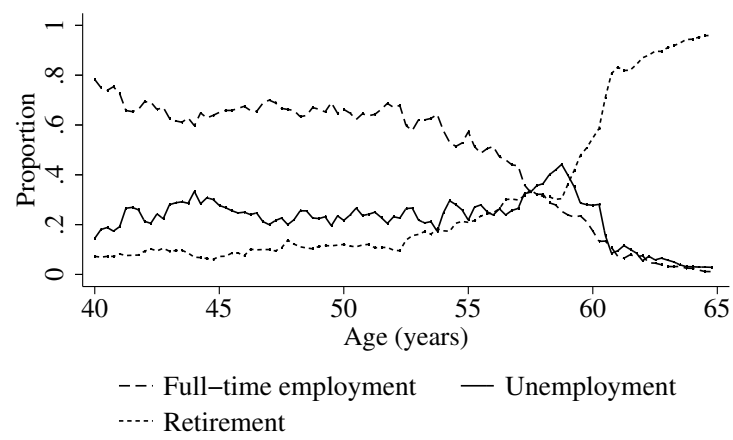

averaged over the whole age distribution, the employment rate is about 10 percentage points higher in west Germany than in the east, and older east Germans have a higher propensity to retire than west Germans of the same age. These differences are likely to be related to the relatively poor economic conditions in east Germany.

The SOEP data set includes individuals' gross earnings in the month prior to the interview date. Using the corresponding working hours, including hours of payed overtime work, we construct an hourly wage measure. We follow Fuchs-Schuendeln and Schuendeln (2005) and construct a measure of individual-level wealth based on the yearly financial information available in the SOEP. Specifically, an individual's wealth is defined as the sum of non-property wealth, computed from capital income assuming a real rate of return of $3 \%$, and net property equity. We convert wealth and wages into year 2000 prices using the Retail Price Index. In our sample, the average gross hourly wage is 15.65 Euros and average individual wealth is 40037 Euros.

\subsection{Human Mortality Database (HMD)}

We obtain information about longevity in Germany from the relevant life tables in the Human Mortality Database (HMD) ${ }^{33}$ The life tables include survival probabilities and life expectancies that vary by age, birth cohort, region of residence (east or west Germany) and gender and are available for the years 1991 - 2007. Based on the information in the HMD, we assign a demographic group-specific and cohort-specific survival probability and life expectancy to each

\footnotetext{
${ }^{33}$ Human Mortality Database is provided by the University of California, Berkeley (USA) and Max Planck Institute for Demographic Research (Germany). The database is available at www.mortality.org.
} 
Figure 2: Life expectancy at age 40 years: evolution over time in east and west Germany

(a) Women

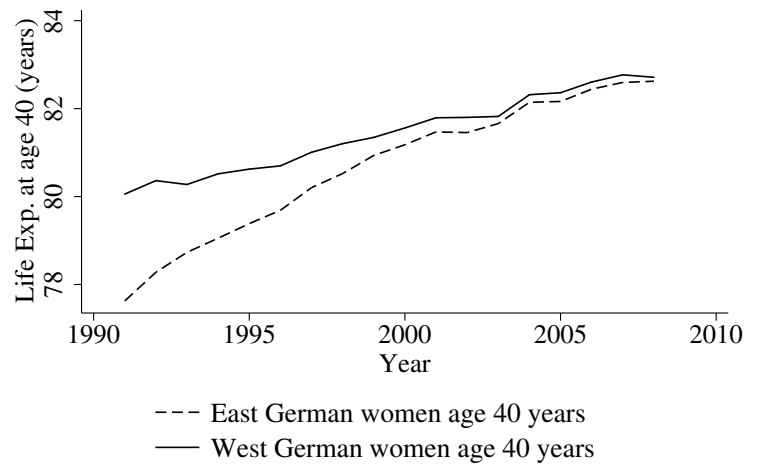

(b) Men

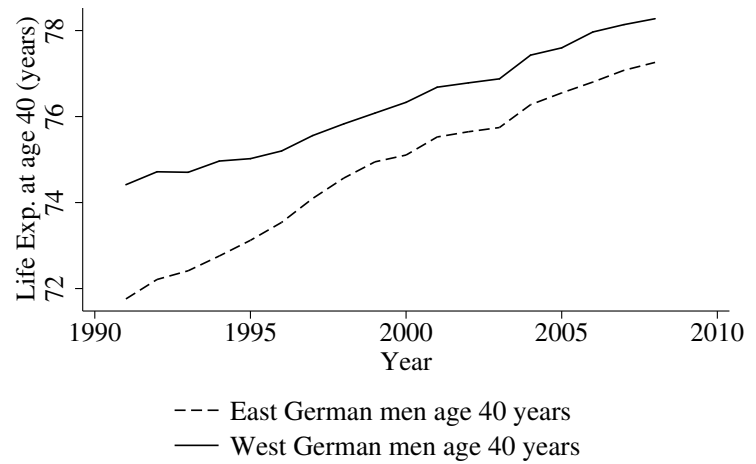

Source: Authors' calculations based on the Human Mortality Database.

observation in our SOEP sample. ${ }^{34}$

Figure 2 shows the evolution over time of life expectancy at age 40 years for east and west German men and women. As expected, we observe longer life expectancies for women and, irrespective of gender or region, an upward trend in life expectancy over time. As well documented in the demographic literature, e.g., Gjonça et al. (2000), life expectancy in east Germany in 1991, immediately after German reunification, was considerably lower than in west Germany: in 1991 a 40 year old east German man expected to live 2.7 years less than his west German counterpart, and the corresponding difference for women was 2.4 years. More important for our purposes are the different time trends by gender and region: between 1991 and 2007, there was a strong east-west convergence in life expectancy for women and moderate east-west convergence for men. Specifically, by 2003 there was hardly any east-west difference in life expectancy for women and by 2007 the east-west life expectancy gap for men had fallen to one year. According to Gjonça et al. (2000), Nolte et al. (2002) and Kibele and Scholz (2008), the leading reason for this convergence was improvements in the medical system in east Germany.

In light of the above documented heterogeneity in life expectancy, in the empirical implementation of our structural life-cycle model we permit variation in life expectancy according to age, birth cohort, gender and region of residence. This maximizes the model's accuracy. Furthermore, by drawing on variation between demographic groups in the extent of improvements in life expectancy over time, we are able to estimate the relationship between life expectancy and retirement decisions, controlling for age, time and cohort effects. This quantity is informative about the extent to which individuals condition behavior on objectively measured life expectancy. As a powerful in-sample goodness of fit test, we compare the relationship between life expectancy and retirement decisions as implied by our estimation results with the corresponding quantity observed in our sample. ${ }^{35}$

\footnotetext{
${ }^{34}$ The HMD does not contain information about marital status. In general, the life expectancy of single individuals tends to be lower than that of married individuals. This may lead our estimate of the subjective time discount factor to be biased downwards. However, we are not concerned about this issue as there is evidence the relationship between life expectancy and marital status is strongest for prime-age individuals and is weak, or even nonexistent, for older individuals (see Johnson et al., 2000). Moreover, it is likely that individuals are less well informed about the relationship between life expectancy and marital status than they are about variation in life expectancy according to gender, region or birth cohort.

${ }^{35}$ In different settings, Alesina and Fuchs-Schuendeln (2007), Fuchs-Schuendeln (2008) and Fuchs-Schuendeln and Schuendeln (2005) also exploit variation generated by German reunification.
} 


\section{Estimation Strategy and Results}

\subsection{Method of Simulated Moments Estimation Method and Identification}

As in Gourinchas and Parker (2002), French (2005) and French and Jones (forthcoming), we estimate the parameters of our model using the Method of Simulated Moments (MSM): parameters are chosen to minimize the distance between a set of moments pertaining to the values of the endogenous variables, namely wages, wealth levels, and employment and retirement outcomes, as observed in our sample and the average values of the same moments in a number of simulated data sets. The construction of each simulated data set starts with the empirical distribution of the exogenous individual characteristics, such as gender, education and region of residence, observed in our sample. Given a trial parameter vector $\theta_{t}$, we draw on a reduced form model in order to simulate the initial values of the endogeneous variables. We then use the abovedescribed structural model as the basis for simulating wage offers and employment, retirement and consumption outcomes in subsequent quarters of the sample period. When simulating data sets, the value function is approximated using the method described in Appendix B.

Suppose that a total of $p$ moments are used in the MSM estimation. Let $M^{o}$ denote the $p$-by-1-dimensional vector of moments constructed from our sample observations. Further, let $M_{k}^{s}\left(\theta_{t}\right)$ denote the same vector of moments constructed using the $k^{\text {th }}$ simulated sample obtained using the parameter vector $\theta_{t}$. The MSM parameter estimates are defined to be the value of $\theta_{t}$ that minimizes the weighted quadratic distance $\left(\bar{M}^{s}\left(\theta_{t}\right)-M^{o}\right)^{\prime} W\left(\bar{M}^{s}\left(\theta_{t}\right)-M^{o}\right)$, where $W$ is a fixed $p$-by-p-dimensional positive semidefinite weighting matrix and $\bar{M}^{s}\left(\theta_{t}\right)$ denotes the value of the vector of simulated moments averaged over $K$ simulated data sets, each obtained using the parameter vector $\theta_{t}{ }^{36}$ Under the conditions stated in Pakes and Pollard (1989), the MSM estimator is consistent and asymptotically normally distributed.

Our estimation procedure uses 265 moments and we estimate 82 parameters. In Appendix C we provide a detailed description of the chosen moments together with information about which parameters are primarily identified by each set of moments. However, we highlight here that the subjective time discount factor, $\delta$, and the utility curvature parameter, $\rho$, are identified from information on wealth holdings and saving behavior according to age. In more detail, information on the average wealth holdings is sufficient to identify either $\delta$ or $\rho$, while variation in wealth according to age allows us to identify both of these parameters. Coefficient estimates obtained from Ordinary Least Squared (OLS) regressions of wages and transitions between labor market states on demographic variables provide moments that identify the effects of observed individual characteristics on wages, job offers and involuntary separations. Meanwhile, moments that describe the persistence in wages and in employment outcomes provide identifying information about the parameters appearing in the distributions of the permanent and persistent unobservables.

We now explain our strategy for accounting for selectivity in the sample wage observations.

\footnotetext{
${ }^{36}$ For the purpose of estimation, we set $K=5$. We thus simulate the employment, retirement and consumption decisions of around 12000 hypothetical individuals in a total of approximately 200000 time periods. Employing the optimal weighting matrix, that is the inverse covariance matrix of the chosen moments, can lead to small sample bias (see Altonji and Segal, 1996). Therefore, we use a diagonal weighting matrix with diagonal elements equal to the inverse of the variances of the sample moments, estimated by bootstrap re-sampling with clustering at the individual level.
} 
As described above in Section 3.1, we observe wages in the sample only in quarters coinciding with the administration of the annual SOEP survey and only for employed individuals who answered all required survey questions. In the MSM estimation routine we recognize these characteristics of our sample by matching moments based on sample wage observations with moments constructed using simulated wage draws that have survived the same selection mechanisms as the sample wage observations. ${ }^{37}$ In particular, a simulated wage draw is included in the construction of the simulated moments if and only if: (i) employment is the individual's optimal choice in the simulated sample; (ii) the quarter is one in which the individual was surveyed; and (iii) the observation survived random elimination of accepted wage draws designed to account for non-random non-response. ${ }^{38}$ Non-labor income and non-linearities in the tax and transfer schedules provide exclusion restrictions and thus ensure that identification of the parameters in the wage equation is not reliant purely on functional form.

Appendix D provides details concerning our treatment of the initial conditions. This section also contains our estimates of the parameters that characterize the initial conditions. We note here that the parameters appearing in the initial conditions are estimated jointly with the structural parameters. Further, by including unobservables that may affect both the initial conditions and subsequent behavior, our estimation methodology accounts fully for the endogeneity of the initial observations of individuals' experience, wages, wealth and employment status. ${ }^{39}$

\subsection{Goodness of Fit and Structural Parameter Estimates}

In Appendix E we show that our model fits accurately important aspects of individuals' observed behavior. In particular, we demonstrate that our model is able to replicate observed features of: the distributions of wages and changes in wages; life-cycle labor supply and retirement behavior; the age profile of wealth; and the patterns of transitions between employment and unemployment. Additionally, we highlight here that the estimated model is able to fit the observed relationship between life expectancy and retirement; thus we conclude that our model provides a sound basis for counterfactual policy simulations which investigate the effect of life expectancy on life-cycle behavior. In more detail, we obtain a summary measure of the observed relationship between life expectancy and retirement by running an OLS regression of retirement on age 65 life expectancy, age dummies, cohort dummies and time dummies. Note that we are able to separate cohort effects from the effect of life expectancy due to the presence of differences between demographic groups in the extent of improvements in life expectancy over time. The coefficient on life expectancy in this OLS regression is -0.066 (with a robust individual-level clustered standard error of 0.027). Meanwhile, the corresponding coefficient on life expectancy

\footnotetext{
${ }^{37}$ Note that our structural model features the joint determination of wage and employment outcomes and therefore accepted simulated wage offers are subject to the same selectivity as sample wage observations.

${ }^{38}$ In more detail: we estimate the probability of an employed individual refusing to answer one or more of the survey questions necessary to construct an hourly wage measure. We then exclude the simulated wage draws of employed individuals with the same probability. This method assumes that survey non-response is based purely on observed individual characteristics.

${ }^{39}$ Health, measured by an indicator of the individual having health problems that limit daily activities, enters the model as a stochastic and exogenous state variable. We estimate the parameters of an equation of motion for health in which an individual's age $t$ health status is a function of health status in the previous period, age and demographic variables. The parameters from this initial estimation are used to simulate the evolution of health when estimating the parameters of the structural model.
} 
Table 1: Structural parameter estimates

\begin{tabular}{|c|c|c|}
\hline & \multicolumn{2}{|c|}{ Coefficient Standard Error } \\
\hline \multicolumn{3}{|l|}{ Wage Equation } \\
\hline Intercept & 1.564 & 0.076 \\
\hline Male & 0.069 & 0.056 \\
\hline West German & 0.335 & 0.046 \\
\hline Male $\times$ West German & 0.154 & 0.065 \\
\hline Education (years)/10 & 0.834 & 0.053 \\
\hline Experience (years) $/ 50$ & 0.330 & 0.090 \\
\hline Native German & 0.079 & 0.035 \\
\hline$($ Age -54$) \mathrm{I}(54 \leq$ Age $<59) / 10$ & -0.040 & 0.097 \\
\hline$($ Age -59$) \mathrm{I}($ Age $\geq 59) / 10$ & -0.181 & 0.138 \\
\hline Health problems & -0.038 & 0.033 \\
\hline Probability of receiving a new match-specific effect (П) & 0.148 & 0.048 \\
\hline Standard deviation of match-specific effect $\left(\sigma_{\tau}\right)$ & 0.085 & 0.008 \\
\hline Standard deviation of permanent individual effect $\left(\sigma_{\alpha}\right)$ & 0.222 & 0.034 \\
\hline Standard deviation of transitory shock $\left(\sigma_{v}\right)$ & 0.023 & 0.006 \\
\hline \multicolumn{3}{|l|}{ Job Offer Probability $(\Theta)$} \\
\hline Intercept & -2.374 & -0.144 \\
\hline$($ Age -40$) \mathrm{I}(40 \leq$ Age $<54) / 14$ & -0.278 & 0.166 \\
\hline$($ Age -54$) \mathrm{I}(54 \leq$ Age $<59) / 5$ & -1.311 & 0.271 \\
\hline$($ Age -59$) \mathrm{I}($ Age $\geq 59) / 5$ & -0.398 & 0.731 \\
\hline West German & 0.814 & 0.133 \\
\hline Health problems & -0.197 & 0.206 \\
\hline Standard deviation of individual effect in job offer probability $\left(\Sigma_{11}^{\mu}\right)$ & 1.029 & 0.064 \\
\hline \multicolumn{3}{|l|}{ Involuntary Separation Probability $(\Gamma)$} \\
\hline Intercept & -4.759 & 0.339 \\
\hline$($ Age -40$) \mathrm{I}(40 \leq$ Age $<54) / 14$ & 2.984 & 0.388 \\
\hline$($ Age -54$) \mathrm{I}(54 \leq$ Age $<59) / 5$ & 0.337 & 0.204 \\
\hline$($ Age -59$) \mathrm{I}($ Age $\geq 59) / 5$ & 2.984 & 0.459 \\
\hline West German & -1.940 & 0.288 \\
\hline Health problems & 0.964 & 0.218 \\
\hline Standard deviation of individual effect in separations $\left(\Sigma_{22}^{\mu}\right)$ & 0.798 & 0.125 \\
\hline Covariance between individual effects in arrivals and separations $\left(\Sigma_{12}^{\mu}\right)$ & -0.657 & 0.124 \\
\hline \multicolumn{3}{|l|}{ Preferences } \\
\hline Coefficient on consumption $(\beta)$ & 5.839 & 1.046 \\
\hline $\operatorname{CRRA}(\rho)$ & 2.565 & 0.138 \\
\hline Mean of complementary parameter $\left(\mu_{\eta}\right)$ & 0.221 & 0.044 \\
\hline Standard deviation of complementarity parameter $\left(\sigma_{\eta}\right)$ & 0.112 & 0.059 \\
\hline Annual subjective time discount factor $(\delta)$ & 0.989 & 0.008 \\
\hline \multicolumn{3}{|c|}{ Probability of Retirement Eligibility on the Grounds of Disability $(\Upsilon)$} \\
\hline Intercept & -0.745 & 0.457 \\
\hline Health problems & 0.797 & 0.414 \\
\hline Male & 0.384 & 0.374 \\
\hline
\end{tabular}

Notes: "Health problems" is an indicator of the individual having health problems that limit daily activities. The mean and standard deviation of the complementarity parameter $\left(\eta_{i}\right)$ after allowing for truncation are 0.231 (with a standard error of 0.023) and 0.106 (with a standard error of 0.028 ) respectively.

implied by our estimation results is -0.059 , which is less than 0.3 of a standard error away from the corresponding observed quantity.

Table 1 shows the estimated values of the parameters appearing in the wage equation, the job offer and involuntary separation probabilities, preferences and the equation describing the 
probability of being eligible for early retirement on the grounds of disability. Looking first at the wage equation, we find that offered wages increase significantly with experience. This finding underlines the importance of experience-based human capital accumulation in the determination of wage offers, and for labor supply behavior over the life-cycle more generally. Ceteris paribus, offered wages are higher in west Germany than in the east, and native Germans and men receive significantly higher wage offers than immigrants and women respectively. We estimate the rate of return to one year of education to be $8.34 \%$. Finally, our estimation results indicate that unobservables play an important role in wage determination. Of all the permitted unobservables, the permanent individual effect $\left(\alpha_{i}\right)$ has the highest standard deviation and therefore has the largest impact on wage offers. This finding implies that unobserved differences in wages are driven primarily by differences in permanent unobserved individual characteristics. However, we also find a significant unobserved match-specific effect; quantitatively, we find that each quarter an individual has a $14.8 \%$ chance of receiving a new match-specific draw. This corresponds to an individual receiving a new match-specific draw on average every 6.8 quarters.

The job offer and involuntary separation probabilities display clear age patterns: older individuals are less likely to receive a job offer and are more likely to be subject to an involuntary separation than younger individuals. As expected, those in poor health and those living in east Germany are relatively likely to be subject to an involuntary separation and are relatively unlikely to receive a job offer. Unobserved individual characteristics have significant effects on the job offer and involuntary separation probabilities. The unobservables affecting job offers and involuntary separations are found to be significantly negatively correlated which is consistent with those unobserved characteristics that contribute positively to involuntary separations also having a negative effect on the probability of receiving a job offer. We find that the probability of being eligible for early retirement on the grounds of disability is positively and significantly (at the $5.4 \%$ level) related to the presence of health problems.

The coefficient on consumption, $\beta$, is significantly greater than zero which implies that individuals' behavior is influenced by the financial incentives associated with employment, retirement and wealth accumulation. We find that $\eta_{i}$, the individual-specific parameter that governs the degree of complementarily between consumption and leisure, displays significant variation over individuals. Moreover, after allowing for truncation of $\eta_{i}$ from above at 0.999 and from below at 0 , the mean value of $\eta_{i}$ is 0.231 . This implies that on average $23.1 \%$ of consumption is required to compensate an employed individual for the disutility of working. Our estimate of the annualized subjective time discount factor is 0.989 , a figure which is in line with previous findings, e.g., De Nardi et al. (2010). Finally, we estimate the CRRA parameter, $\rho$, to be 2.565 and we therefore conclude that individuals are risk averse. Both the subjective time discount factor and the CRRA parameter are precisely estimated, which lays testament to the quality and relevance of the available consumption information. 


\section{Policy Analysis}

\subsection{Longevity, Optimal Life-cycle Behavior and Net Government Revenue}

The determination of how public pension systems may be reformed to ensure their financial stability in the face of improving longevity requires a precise understanding of the behavioral and fiscal implications of increasing life expectancy. We therefore commence our counterfactual policy analysis by using the life-cycle model described above, together with our parameter estimates, to explore the effects of an increase in life expectancy. Specifically, we compare the optimal life-cycle behavior, and associated tax, transfer and pension receipts, of two groups of individuals who differ only with respect to life expectancy. Each individual in the first group is assigned the appropriate gender-specific and region-specific life expectancy of the 1942 birth cohort, that is the life expectancy of an individual from the appropriate demographic group who was 65 years old in 2007. Meanwhile, each individual in the second group is assigned the appropriate predicted individual-specific life expectancy of the 1982 birth cohort, who will reach age 65 years 40 years after individuals in the first group, i.e., in 2047. According to the HMD for Germany, life expectancy at age 65 is anticipated to be on average 6.4 years higher for the 1982 birth cohort than for the 1942 birth cohort. ${ }^{40}$ For both groups of individuals, we fix the distribution of all characteristics other than life expectancy at that observed in our sample and we impose the year 2007 tax, transfer and pension systems throughout.

Figures 3(a) - 3(c) show how the rates of employment, unemployment and retirement are affected by the 6.4 year increase in age 65 life expectancy anticipated to occur over the 40 years that separate the 1942 and 1982 birth cohorts. We find that among individuals aged under 57 years there is little adjustment in retirement behavior. ${ }^{41}$ Instead, a small proportion of such individuals, approximately 0.1 percent, switch from unemployment to employment. In contrast, the employment, unemployment and retirement behavior of individuals aged over 57 years displays a strong dependence on life expectancy. In particular, we find that the considered 6.4 year increase in age 65 life expectancy leads individuals aged over 57 years to postpone retirement. The magnitude of this effect is relatively large: the increase in life expectancy under consideration reduces the retirement rate by an average of approximately 1 percentage point for those aged 57-64.75 years and by almost 3 percentage points for individuals aged 64 years. Intuitively, an increase in life expectancy raises the expected future returns to both current employment and current unemployment (provided that the individual is eligible for Unemployment Insurance), through which individuals are able to accumulate pension points, and hence leads to a substitution away from retirement.

The postponement of retirement among individuals approaching the full pensionable age of 65 years is balanced by an increase in unemployment and, to a lesser extent, an increase in employment. For example, the 6.4 year increase in age 65 life expectancy under consideration causes the unemployment rate of individuals aged 64 years to increase by 2 percentage points

\footnotetext{
${ }^{40}$ The corresponding increase in life expectancy at birth over the 40 years that separate these two cohorts is roughly 10 years. Therefore, the anticipated evolution of life expectancy in Germany is broadly in line with the widespread trend in life expectancy in the developed world documented by Oeppen and Vaupel (2002).

${ }^{41}$ Prior to age 57 years we predict a small increase in retirement. This effect can be explained by higher employment rates earlier in the life-cycle which, ceteris paribus, make retirement financially more attractive later in the life-cycle.
} 
Figure 3: Life expectancy improvement between 1942 and 1982 birth cohorts:

Effects over the life-cycle on rates of employment, unemployment and retirement and on net Government revenue per person per month

(a) Employment

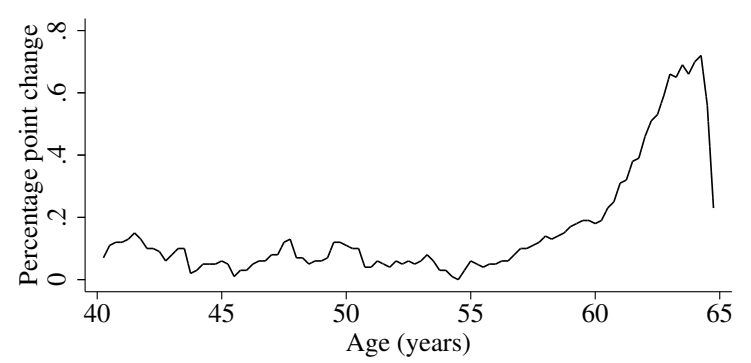

(c) Retirement

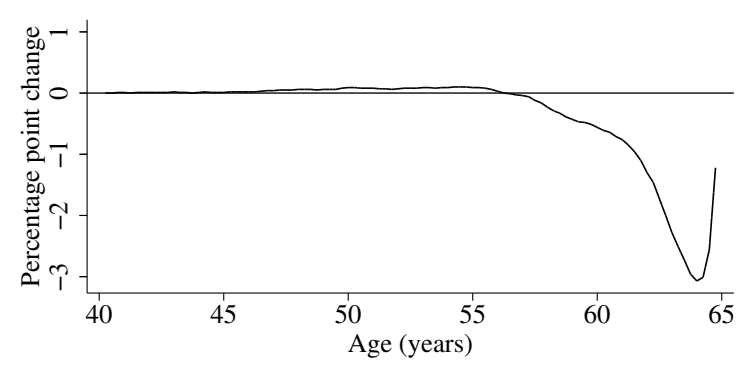

(b) Unemployment

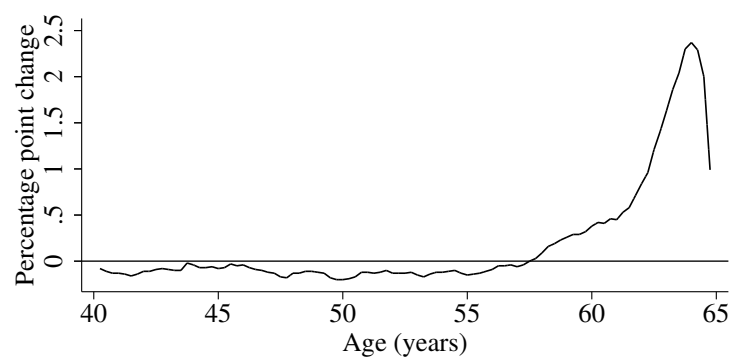

(d) Net Government revenue per person per month

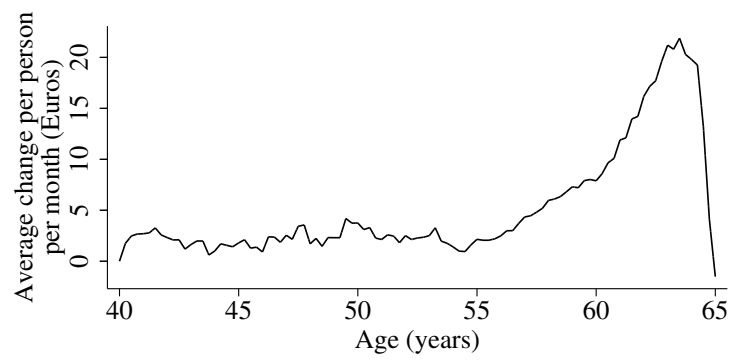

Notes: All figures refer to individuals aged 40-64.75 years.

while the corresponding increase in the employment rate is only 0.85 of a percentage point. There are two factors which lead the postponement of retirement to be balanced predominantly by higher unemployment. First, our results imply a relatively low job offer probability and a relatively high rate of involuntary separations for older individuals. Therefore those wanting to retire later may have difficulty finding or keeping a job. Second, the Unemployment Insurance system provides a strong incentive for individuals to use unemployment as a stepping-stone into retirement. Specifically, the relatively long entitlement periods for Unemployment Insurance benefits for older individuals (see Appendix A.1) make it attractive for such individuals to enter retirement after a spell of unemployment. The design of the public pension system increases this incentive because individuals collecting Unemployment Insurance benefits accumulate additional pension points which increase public pension benefits upon retirement.

Next, we consider the effect of an increase in life expectancy on net Government revenue, NGR, which takes the following form

$$
\text { NGR }=\text { Income Tax }+2 \times \text { SSC }- \text { UIB }- \text { SAB }- \text { Public Pension Benefits, }
$$

where Income Tax consists of taxes paid on labor income, pension income and interest income from wealth holdings, SSC denotes individual Social Security Contributions (this figure is multiplied by two because firms must match individuals' contributions), and UIB and SAB correspond 
Table 2: Life expectancy improvement between 1942 and 1982 birth cohorts:

Effects on average net Government revenue per person, years of employment post age 40 years, retirement age and weighted pension points upon retirement.

\begin{tabular}{cccccccccc}
\hline \hline Birth & Public Pension: & Average Life & \multicolumn{2}{c}{ Net Government Revenue Per Person } & Yr Emp. & \multirow{2}{*}{ Avet. Age } & Pension \\
Cohort & FPA/ Pension Value & Exp. at 65 & All & Emp. & Unemp. & Retired & Age $\geq 40$ & Reints \\
\hline 1942 & 65/ 2007 System & 83.3 & 57005 & 288249 & -30682 & -200562 & 17.75 & 62.35 & 39.29 \\
1982 & $65 / 2007$ System & 89.7 & -18446 & 294666 & -31995 & -281117 & 17.78 & 62.43 & 39.34 \\
\hline Change & (1982 - 1942 cohort) & 6.4 & -75451 & 6418 & -1312 & -80556 & 0.03 & 0.08 & 0.05 \\
\hline
\end{tabular}

Notes: "FPA" refers to the full pensionable age and "Pension Value" is the per-year value of public pension benefits. "Net Government Revenue Per Person" is the average per person (starting at age 40 years and continuing until death) net revenue received by the Government, measured in Euors. "Yr Emp. Age $\geq 40$ " is the average number of years of employment post age 40 years and "Ret. Age" is the average age of retirement. "Pension Points" is the average number of weighted pension points accumulated prior to the date of retirement.

respectively to Unemployment Insurance benefits and Social Assistance benefits. We analyze here the effect of life expectancy on average net Government revenue per person per month according to age, focusing on those aged below the full pensionable age of 65 years. Meanwhile, in the more aggregated analysis presented in the next paragraph we additionally include net transfers made to individuals aged 65 years and above. Figure 3(d) shows that the 6.4 year increase in life expectancy anticipated to occur between the 1942 and 1982 birth cohorts leads, via optimizing individuals adjusting employment, retirement and consumption behavior, to an increase in average monthly net Government revenue per person at every age prior to the full pensionable age of 65 years. Thus, the increase in pension demands associated with longer life expectancy is partly offset by higher tax receipts from individuals aged below the full pensionable age. In line with the age profile of responses in labor supply and retirement behavior, we find that the increase in average monthly per-person net Government revenue is largest for individuals aged 64 years: for such individuals, average net Government revenue increases by approximately 20 Euros per person per month.

We now extend our analysis of the fiscal effects for the Government of an increase in life expectancy by additionally considering net transfers made to individuals aged equal to or above the full pensionable age of 65 years. In more detail, based on the estimated model, we determine the net transfer made to the Government by each individual in each quarter of his or her life, starting at age 40 years and continuing until death. Summing over an individual's life yields the total post age 40 years net transfer made by the individual to the Government. Finally, averaging over individuals provides an estimate of average per-person net Government revenue. Table 2 shows that, holding fixed the tax, transfer and pension systems, the increase in life expectancy anticipated to occur between the 1942 and 1982 birth cohorts leads to a substantial deterioration of Government's net budgetary position. Specifically, the considered 6.4 year increase in age 65 life expectancy leads to a decrease in average per-person net Government revenue of 75451 Euros. Decomposing, the increase in life expectancy under consideration has a minor positive effect on the average transfer made to unemployed individuals, and causes net Government revenue received from employed individuals to increase by an average of 6418 Euros per person. However, the average net transfer made to retired individuals increase by 80556 Euros per person. This dramatic increase in the average net transfer made to retired individuals is due mainly to the mechanical effect of longer life expectancy increasing the expected duration over 
Table 3: Life expectancy improvement between 1942 and 1982 birth cohorts:

Implications for wealth accumulation and consumption

\begin{tabular}{cccccccc}
\hline \hline Birth & Public Pension: & Wealth on & Monthly Income & Total Cons. & \multicolumn{3}{c}{ Monthly Consumption } \\
\cline { 5 - 8 } Cohort & FPA/Pension Value & Retirement & from Wealth & post Age 40 & Age 45 & Age 55 FPA (Age 65) \\
\hline 1942 & 65/ 2007 System & 27371 & 146 & 571197 & 1291 & 1341 & 1054 \\
1982 & 65/ 2007 System & 28402 & 126 & 665166 & 1294 & 1336 & 1035 \\
\hline Difference & $(1982-1942$ cohort): & 1031 & -20 & 93969 & 3 & -5 & -19 \\
\hline
\end{tabular}

Notes: "Wealth on Retirement" is average per-person private wealth at the date of retirement. "Monthly Income from Wealth" is the average per-person actuarially fair monthly annuity income wealth at the date of retirement. Consumption (Cons.) figures are averaged over individuals. Consumption and wealth figures are in Euros. "FPA" refers to the full pensionable age.

which public pension benefits are payable. ${ }^{42}$

Lastly, we analyze the effect of life expectancy on consumption choices and wealth accumulation. Intuitively, in response to an increase in life expectancy, optimizing individuals adjust consumption in order to equalize the higher return to saving with marginal utility of contemporaneous consumption, which in turn depends on current employment behavior. Empirically, Table 3 shows that the considered 6.4 year increase in age 65 life expectancy leads average individual wealth at the date of retirement to increase by 1031 Euros. ${ }^{43}$ This result, which is in line with the findings of De Nardi et al. (2009) and De Nardi et al. (2010), demonstrates that the ability to alter wealth accumulation decisions provides individuals with a valuable means of adjusting behavior in response to an improvement in longevity. Recognition of this fact is necessary for understanding the effects of reductions in the generosity of the public pension system, discussed below in Section 5.2.

Table 3 further shows that the increase in life expectancy anticipated to occur between the 1942 and 1982 birth cohorts leads to a fall in the income stream that retired individuals are able to obtain from accumulated wealth of the order of 21 Euros per month. Thus, increased wealth accumulation prior to retirement is insufficient to compensate for the effect of higher life expectancy on the feasible income stream obtainable from wealth holdings. Due to increased pension point accumulation prior to retirement, we find that the considered increase in age 65 life expectancy causes average monthly consumption at age 65 years and above to fall by slightly less than the decline in the feasible income stream obtainable from accumulated wealth. Specifically, consumption at age 65 years and above falls by an average of 19 Euros per month. We further note that the increase in age 65 life expectancy under consideration is associated with only small adjustments in monthly consumption at ages 45 and 55 years. Therefore, as a first approximation, the extra employment income obtained by such individuals is being used solely to increase wealth holdings.

Notwithstanding the fall in the average monthly consumption of retired individuals, the 6.4 year increase in age 65 years life expectancy anticipated to occur between the 1942 and 1982 birth cohorts causes expected total per-person post age 40 years consumption to increase by approximately 94000 Euros. Roughly 75000 Euros of this increase is accounted for by increased transfers from the Government (see Table 2) while the remaining 19000 Euros is financed from

\footnotetext{
${ }^{42}$ Additionally, transfer payments to retired individuals increase slightly due to the higher value of public pension benefits, which reflects the increase in average pension points accumulated prior to retirement.

${ }^{43}$ This effect consists of a component arising from changes in savings decisions and a component due to alterations in the timing of entry into retirement.
} 
increased wage income and additional interest income from wealth. ${ }^{44}$

\subsection{Fiscal and Behavioral Effects of Reductions in Public Pension Generosity}

The substantial deterioration in the Government's budgetary position created by a readily foreseeable increase in life expectancy confirms a role for reforms to the public pension system designed to address the fiscal costs created by improving longevity. With this in mind, we examine the effectiveness of reductions in the generosity of the public pension system at counterbalancing the aggregate fiscal consequences of increasing life expectancy. Specifically, we consider the 6.4 year increase in age 65 life expectancy anticipated to occur over the 40 years that separate the 1942 and 1982 birth cohorts and we analyze the behavioral and fiscal effects of: (i) increases in the full pensionable age; and (ii) cuts in the per-year value of public pension benefits. As in Section 5.1, when conducting this analysis we fix the distribution of all characteristics other than life expectancy at that observed in our sample and we impose the year 2007 tax and transfer systems throughout. Unless otherwise indicated, we use the 2007 pension system.

The top panel of Table 4 summarizes the effects on labor market behavior and net Government revenue of increasing the full pensionable age from its current value of 65 years. ${ }^{45}$ We find that increases in the full pensionable age have strong effects on labor supply behavior. Specifically, such reforms lead individuals to postpone retirement and to increase years of employment prior to retirement. Indeed, within the range of reforms under consideration, a one year increase in the full pensionable age causes the average retirement age to increase by approximately 0.9 of a year, and causes average years of employment prior to retirement to increase by 0.85 of a year. Increases in the full pensionable lead to appreciable increases in the average net transfer made to the Government from employed individuals, and cause substantial reductions in the average transfer payment made to retired individuals.

Overall, our calculations suggest that the full pensionable age must be increased to 69.34 years in order to offset the fiscal consequences for the Government of 40 years worth of growth in life expectancy. In other words, a 6.4 year increase in age 65 life expectancy requires that the full pensionable age be increased by 4.34 years in order to restore the Government's budgetary position. ${ }^{46}$ This policy eliminates the approximately 75000 Euros per-person deficit created by 40 years worth of growth in life expectancy via two main routes. First, an increase of 4.34 years in the full pensionable age increases the net transfer received by the Government from employed individuals by an average of approximately 54000 Euros per person. Second, the net transfer made to retired individuals declines by an average of roughly 23000 Euros per person.

The bottom panel of Table 4 summarizes the effects on labor market behavior and net Government revenue of cuts in the per-year value of public pension benefits. Throughout these calculations the full pensionable age is held fixed at its current value of 65 years. This set of

\footnotetext{
${ }^{44}$ One of the effects of the improvement in longevity under study is to cause the survival rate prior to the full pensionable age of 65 years to increase. Ceteris paribus, this change leads to an increase in expected life-time wage income. Indeed, further analysis (not reported) shows that this effect accounts for the majority of the non-Government financed increase in expected total post age 40 years consumption.

${ }^{45}$ When conducting this analysis the age-based requirements for early retirement were increased in line with the increase in the full pensionable age.

${ }^{46}$ This figure was obtained by computing the net Government revenue associated with full pensionable ages of 69.25 years and 69.5 years and then interpolating linearly to find the increase in the full pensionable age that offsets exactly the fiscal consequences of 40 years worth of growth in life expectancy.
} 
Table 4: Public pension reforms:

Effects on average net Government revenue per person, years of employment post age 40 years, retirement age and weighted pension points upon retirement

\begin{tabular}{|c|c|c|c|c|c|c|c|c|}
\hline \multirow{2}{*}{$\begin{array}{l}\text { Birth } \\
\text { Cohort }\end{array}$} & \multirow{2}{*}{$\begin{array}{l}\text { Public Pension: } \\
\text { FPA/Pension Value }\end{array}$} & \multicolumn{4}{|c|}{ Net Government Revenue Per Person } & \multirow{2}{*}{$\begin{array}{l}\text { Yr Emp. } \\
\text { Age } \geq 40\end{array}$} & \multirow{2}{*}{ Ret. Age } & \multirow{2}{*}{$\begin{array}{c}\text { Pension } \\
\text { Points }\end{array}$} \\
\hline & & All & Employed & Unemployed & Retired & & & \\
\hline \multicolumn{9}{|c|}{ Increased full pensionable age: } \\
\hline 1982 & 66/ 2007 System & -65 & 308534 & -31787 & -276812 & 18.70 & 63.37 & 40.31 \\
\hline 1982 & 67/ 2007 System & 16392 & 320443 & -32192 & -271860 & 19.52 & 26 & 41.18 \\
\hline 1982 & 68/2007 System & 33096 & 332352 & -33240 & -266016 & 20.31 & 65.24 & 42.04 \\
\hline 1982 & 69/ 2007 System & 48140 & 341927 & -33952 & -259835 & 20.99 & 66. & 42.76 \\
\hline 1982 & 70/ 2007 System & 68620 & 356808 & -33393 & -254796 & 21.99 & & 43.84 \\
\hline 1982 & 71/ 2007 System & 88413 & 371205 & 3269 & -249522 & 22.97 & & 44.85 \\
\hline \multicolumn{9}{|c|}{ Revenue neutral full pensionable age: } \\
\hline 1982 & 69.34/ 2007 System & 57005 & 348609 & -33314 & -258290 & 21.42 & 66.39 & 43.24 \\
\hline \multicolumn{9}{|c|}{ Cut in the per-year value of public pension benefits: } \\
\hline 1982 & $65 / 2007$ System $-5 \%$ & -6198 & 295143 & -32936 & -268405 & 17.79 & 62.58 & 39.39 \\
\hline 1982 & 65/ 2007 System - 10\% & 5427 & 295281 & -33919 & -255936 & 17.79 & 62.72 & 39.41 \\
\hline 1982 & $65 / 2007$ System - 15\% & 16242 & 295205 & -35060 & -243903 & 17.77 & 62.86 & 39.43 \\
\hline 1982 & $65 / 2007$ System - 20\% & 26699 & 295184 & -36275 & -232211 & 17.75 & 63.02 & 39.45 \\
\hline 1982 & 65/ 2007 System $-25 \%$ & 36448 & 294996 & -37609 & -220938 & 17.72 & 63.19 & 39.47 \\
\hline 1982 & $65 / 2007$ System $-30 \%$ & 45290 & 294589 & -38998 & -210301 & 17.70 & 63.36 & 39.48 \\
\hline 1982 & $65 / 2007$ System $-35 \%$ & 53135 & 294053 & -40520 & -200398 & 17.66 & 63.54 & 39.48 \\
\hline 1982 & $65 / 2007$ System $-40 \%$ & 60231 & 293466 & -41806 & -191429 & 17.62 & 63.69 & 39.47 \\
\hline \multicolumn{9}{|c|}{ Revenue neutral cut in the per-year value of public pension benefits: } \\
\hline 1982 & $65 / 2007$ System $-37.7 \%$ & 57005 & 293666 & -41205 & -195456 & 17.63 & 63.62 & 39.47 \\
\hline
\end{tabular}

Notes: See Table 2.

reforms has hardly any effect on individuals' optimal life-cycle employment behavior and induces a relatively minor postponement of retirement, of the order of 0.20 of a year for every 5 percentage point cut in the per-year value of public pension benefits. In terms of net Government revenue, cuts in the per-year value of public pension benefits have essentially no effect on average net Government revenue received from employed individuals. Meanwhile, total life-cycle transfers made to unemployed individuals increase by an average of approximately 1100 Euros per person for every 5 percentage point cut in the per-year value of public pension benefits. However, cuts in the per-year value of public pension benefits cause net Government revenue to increase due to considerably lower net transfers to retired individuals. We find that the per-period value of public pension benefits must be reduced by $37.7 \%$ in order to counterbalance the fiscal consequences of 40 years worth of growth in life expectancy.

We conclude our analysis of public pension reforms with Table 5, which explores the effects of increases in the full pensionable age and cuts in the per-year value of public pension benefits on individuals' wealth accumulation and consumption behavior. We find that increases in the full pensionable age have little effect on wealth accumulated at the date of retirement or on monthly consumption at ages 45 or 55 years. The main routes, therefore, by which individuals re-optimize in response to an increase in the full pensionable age are via employment behavior and the timing of retirement, as documented in Table 4. Increases in the full pensionable age do, however, lead expected total post age 40 years consumption to increase, a change that can be linked to increased consumption among retirees. In particular, consumption at the full pensionable age, i.e., the first date at which all individuals are necessarily retired, increases by an average of 122 Euros per month when the full pensionable age is increased from 65 years to 71 years. This change reflects predominantly the returns to higher life-cycle employment which 
Table 5: Public pension reforms:

Implications for wealth accumulation and consumption

\begin{tabular}{|c|c|c|c|c|c|c|c|}
\hline \multirow{2}{*}{$\begin{array}{l}\text { Birth } \\
\text { Cohort }\end{array}$} & \multirow{2}{*}{$\begin{array}{c}\text { Public Pension: } \\
\text { FPA/Pension Value }\end{array}$} & \multirow{2}{*}{$\begin{array}{l}\text { Wealth on } \\
\text { Retirement }\end{array}$} & \multirow{2}{*}{$\begin{array}{l}\text { Monthly Income } \\
\text { from Wealth }\end{array}$} & \multirow{2}{*}{$\begin{array}{l}\text { Total Cons. } \\
\text { post age } 40\end{array}$} & \multicolumn{3}{|c|}{ Monthly Consumption } \\
\hline & & & & & Age 45 & Age 55 & FPA \\
\hline \multicolumn{8}{|c|}{ Increased full pensionable age: } \\
\hline 1982 & 66/ 2007 System & 27593 & 124 & 674758 & 1300 & 1336 & 1053 \\
\hline 1982 & 67/ 2007 System & 28266 & 130 & 683404 & 1296 & 1334 & 1074 \\
\hline 1982 & 68/2007 System & 28001 & 131 & 690998 & 1296 & 1340 & 1091 \\
\hline 1982 & 69/2007 System & 28323 & 135 & 696110 & 1296 & 1338 & 1104 \\
\hline 1982 & 70/ 2007 System & 27928 & 137 & 705731 & 1298 & 1339 & 1127 \\
\hline 1982 & 71/ 2007 System & 28502 & 144 & 715758 & 1296 & 1339 & 1157 \\
\hline \multicolumn{8}{|c|}{ Revenue neutral full pensionable age: } \\
\hline 1982 & 69.34/ 2007 System & 27979 & 135 & 700469 & 1298 & 1339 & 1114 \\
\hline \multicolumn{8}{|c|}{ Cut in the per-year value of public pension benefits: } \\
\hline 1982 & 65/ 2007 System - 5\% & 29751 & 132 & 654648 & 1291 & 1329 & 1004 \\
\hline 1982 & $65 / 2007$ System $-10 \%$ & 31022 & 138 & 644059 & 1289 & 1321 & 973 \\
\hline 1982 & $65 / 2007$ System $-15 \%$ & 32280 & 144 & 633804 & 1285 & 1314 & 943 \\
\hline 1982 & $65 / 2007$ System $-20 \%$ & 33369 & 149 & 623932 & 1282 & 1306 & 914 \\
\hline 1982 & $65 / 2007$ System $-25 \%$ & 34229 & 153 & 614358 & 1279 & 1300 & 886 \\
\hline 1982 & $65 / 2007$ System $-30 \%$ & 34747 & 156 & 605155 & 1277 & 1294 & 858 \\
\hline 1982 & $65 / 2007$ System $-35 \%$ & 35055 & 158 & 596543 & 1276 & 1289 & 831 \\
\hline 1982 & $65 / 2007$ System - 40\% & 35249 & 160 & 588536 & 1274 & 1284 & 806 \\
\hline \multicolumn{8}{|c|}{ Revenue neutral cut in the per-year value of public pension benefits: } \\
\hline 1982 & $65 / 2007$ System - 37.7\% & 35138 & 157 & 592049 & 1275 & 1286 & 817 \\
\hline
\end{tabular}

Notes: See Table 3.

occur through the intertemporal linkages present in the public pension system; increased income from accumulated wealth, arising from the postponement of retirement, also contributes to the higher average consumption of retirees, however the magnitude of this effect is relatively small.

In contrast, as illustrated in the bottom panel of Table 5, we find that cuts in the per-year value of public pension benefits have a dramatic positive effect on wealth accumulation: for the reforms under consideration, each 5 percentage point cut in the per-year value of public pension benefits leads average wealth accumulated at the date of retirement to increase by over 1000 Euros per person. Moreover, given the modest effect of cuts in the per-year value of public pension benefits on the timing of retirement, increased wealth accumulation translates into a higher feasible income stream obtainable upon retirement from accumulated wealth. However, increased wealth accumulation prior to retirement is not sufficient to counter the income effects of cuts in the per-year value of public pension benefits. Therefore, following a cut in the per-year value of public pension benefits, monthly consumption at the full pensionable age decreases, as does expected total post age 40 years consumption.

In summary, an increase in the full pensionable age of 4.34 years and a cut in the per-year value of public pension benefits of $37.7 \%$ both neutralize the effect on the Government's net revenue position of the 6.4 year increase in age 65 life expectancy anticipated to occur during the 40 years that separate the 1942 and 1982 birth cohorts. However, these two revenue-equivalent policy approaches have dramatically different implications for individuals' labor supply and retirement behavior, for wealth accumulation and for consumption outcomes. Notably, reinstating the Government's budgetary position by increasing the full pensionable age leads to a higher average retirement age and a higher employment rate as compared to if the Government's budgetary position is preserved by cutting the per-year value of public pension benefits; however, cutting the per-year value of public pension benefits has a much larger effect on wealth accumu- 
lation than does increasing in the full pensionable age. Arguably most importantly, of these two revenue-equivalent policies, expected total post age 40 years consumption is highest following the increase in the full pensionable age. We conclude, therefore, that a reduction in public pension generosity operationalized via an increase in the full pensionable age generates a greater increase in productivity than a revenue-equivalent reform which entails a cut in the per-year value of public pension benefits.

\section{Conclusion}

The life expectancy of individuals living in the developed world is anticipated to increase appreciably over the coming decades. In Germany, for example, during the 40 years that separate the 1942 and 1982 birth cohorts life expectancy at age 65 is projected to increase by 6.4 years. This substantial demographic change poses a threat to the sustainability of many defined benefit public pension systems. Using a rich dynamic structural life-cycle model in which individuals' optimal employment, retirement and consumption decisions depend, inter alia, on life expectancy and the design of the public pension system, we have examined the behavioral and fiscal implications of improving longevity. Moreover, we have drawn on the estimated model and explored the effects of reductions in the generosity of the public pension system.

Our results show that, in the context of Germany, 40 years worth of growth in life expectancy leads to a substantial deterioration in the Government's net budgetary position. This outcome arises despite a mitigating effect due to individuals optimally increasing employment and postponing retirement in response to an improvement in longevity. This finding confirms the need for policy reforms that address the additional fiscal demands on Government finances created by an ageing society. Counterfactual policy simulations based on the estimated model show that the full pensionable age must be increased by 4.34 years, from 65 years to 69.34 years, in order to offset the fiscal consequences for the Government of the 6.4 year increase in age 65 life expectancy anticipated to occur over the 40 years that separate the 1942 and 1982 birth cohorts. Alternatively, given the current full pensionable age of 65 years, we show that the Government's net budgetary position can be reinstated via a cut of $37.7 \%$ in the per-year value of public pension benefits. The latter approach to counterbalancing the fiscal consequences of 40 years worth of growth in life expectancy generates the greatest increase in wealth accumulation. However, comparing these two revenue equivalent policies, we find that the employment rate and expected total per-person post age 40 years consumption are both markedly higher if the reduction in public pension generosity is instead achieved via an increase in the full pensionable age.

In addition to making a significant contribution to the current policy debate on public pension reform, this paper provides several insights regarding the analysis of individual behavior over the life-cycle. Notably, the incentives induced by the pension system have been shown to play an important role in explaining individuals' life-cycle employment, retirement and consumption decisions. We conclude, therefore, that a detailed depiction of the pension system should be central to the modeling of many aspects of life-cycle behavior. Perhaps more importantly, the results of our counterfactual policy simulations demonstrate that an increase in life expectancy has implications for optimal individual behavior prior to the full pensionable age. Our analysis 
indicates, therefore, that an accurate understanding of the fiscal and behavioral implications of improving longevity requires a life-cycle approach which permits behavioral responses in terms of employment, retirement and consumption. Previously, life-cycle modeling has been used to understand the implications of life expectancy for decisions related to wealth accumulation. The life-cycle model developed and estimated in this paper recognizes the dependence of employment and retirement decisions, as well as consumption choices, on life expectancy. Our analysis therefore extends previous research along an important dimension.

\section{Appendix}

\section{A The German Tax, Transfer and Pension Systems}

This appendix provides further details concerning the German tax, transfer and pension systems. The parameters and rules described here, together with the discussion provided in Section 2.4, define work incentives which are an important force driving individuals' life-cycle employment, retirement and consumption behavior. This section closes with a discussion of our approach to modeling individuals' expectations concerning the evolution of the public pension system.

\section{A.1 Tax and Transfer Systems: Further Details}

Table 6 summarizes selected features of tax and transfer system, while Table 7 provides further details concerning the Unemployment Insurance system.

Table 6: Selected features of the German tax and transfer systems: $1991-2007$

\begin{tabular}{|c|c|c|c|c|c|c|c|c|}
\hline & \multicolumn{3}{|c|}{ Social Security Contributions } & \multicolumn{3}{|c|}{ Income tax } & \multicolumn{2}{|c|}{ Social Assistance } \\
\hline Year & $\begin{array}{c}\text { Contribution } \\
\text { rate } \\
(\%)\end{array}$ & $\begin{array}{c}\text { Max. Cont. } \\
\text { west } \\
\text { per month }\end{array}$ & $\begin{array}{c}\text { Max. Cont. } \\
\text { east } \\
\text { per month }\end{array}$ & $\begin{array}{c}\text { Tax free } \\
\text { allowance } \\
\text { per year }\end{array}$ & $\begin{array}{c}\text { Top marginal } \\
\text { tax rate } \\
(\%)\end{array}$ & $\begin{array}{c}\text { Solidarity } \\
\text { tax } \\
(\%)\end{array}$ & $\begin{array}{l}\text { Average } \\
\text { west } \\
\text { per month }\end{array}$ & $\begin{array}{c}\text { Average } \\
\text { east } \\
\text { per month }\end{array}$ \\
\hline 1991 & 17.7 & 3250 & 1700 & 4050 & 53 & 3.3 & 550 & 500 \\
\hline 1992 & 18.4 & 3400 & 2400 & 4050 & 53 & 3.75 & 540 & 520 \\
\hline 1993 & 18.6 & 3600 & 2650 & 4050 & 53 & 0 & 550 & 544 \\
\hline 1994 & 19.4 & 3800 & 2950 & 4050 & 53 & 0 & 557 & 545 \\
\hline 1995 & 19.6 & 3900 & 3200 & 4050 & 53 & 7.5 & 564 & 553 \\
\hline 1996 & 20.1 & 4000 & 3400 & 6021 & 53 & 7.5 & 571 & 560.5 \\
\hline 1997 & 21.0 & 4100 & 3550 & 6021 & 53 & 7.5 & 580 & 569.5 \\
\hline 1998 & 21.1 & 4200 & 3500 & 6156 & 53 & 5.5 & 586 & 575 \\
\hline 1999 & 21.1 & 4250 & 3600 & 6507 & 53 & 5.5 & 594 & 584 \\
\hline 2000 & 20.5 & 4300 & 3550 & 6876 & 51 & 5.5 & 606 & 596 \\
\hline 2001 & 20.4 & 4350 & 3650 & 7200 & 48.5 & 5.5 & 617 & 606 \\
\hline 2002 & 20.6 & 4500 & 3750 & 7200 & 48.5 & 5.5 & 629 & 617 \\
\hline 2003 & 21.0 & 5100 & 4250 & 7200 & 48.5 & 5.5 & 634 & 622 \\
\hline 2004 & 21.0 & 5150 & 4350 & 7632 & 45 & 5.5 & 643 & 631 \\
\hline 2005 & 20.7 & 5200 & 4400 & 7632 & 42 & 5.5 & 653 & 637 \\
\hline 2006 & 21.0 & 5250 & 4400 & 7632 & 42 & 5.5 & 658 & 642 \\
\hline 2007 & 20.3 & 5250 & 4550 & 7632 & 45 & 5.5 & 662 & 645 \\
\hline
\end{tabular}

Notes: Unless indicated otherwise, all figures are in Euros and are expressed in nominal terms. Social Assistance consists of a person-related component that varies by region of residence and individual-specific housing benefits. Housing benefits are limited to the cost of a reasonable apartment, given local property prices and household size. 
Table 7: Maximum Unemployment Insurance entitlement period by age: $1991-2007$

\begin{tabular}{cccc}
\hline \hline Age (years) & Prior to April 1997 & From April 1997 until Jan 2006 & Since February 2006 \\
\hline$<42$ & 12 & 12 & 12 \\
$42-43$ & 18 & 12 & 12 \\
44 & 22 & 12 & 12 \\
$45-46$ & 22 & 18 & 12 \\
$47-48$ & 22 & 22 & 12 \\
$49-51$ & 26 & 22 & 12 \\
$52-53$ & 26 & 26 & 12 \\
54 & 32 & 26 & 18 \\
$55-56$ & 32 & 26 & 18 \\
$\geq 57$ & 32 & 32 & 18 \\
\hline
\end{tabular}

Notes: Adapted from Schmitz and Steiner (2007). Individuals accumulate entitlement to Unemployment Insurance benefits at a rate of one month of Unemployment Insurance entitlement for every two months of employment, up to the relevant age-specific maximum detailed in this table. For the duration of the entitlement period, Unemployment Insurance benefits provide an income of up to $60 \%$ of an individual's net income in his or her most recent job.

\section{A.2 Public Pension System: Further Details}

\section{A.2.1 Pension Point Values}

Table 8 shows the proportionality factors used to compute the value of the non-reduced public pension. This table also shows the adjustment factor applied the wages of east Germans prior to determining the pension point weight.

Table 8: Pension point values (proportionality factors): 1991 - 2007

\begin{tabular}{|c|c|c|c|}
\hline \multirow{2}{*}{ Year } & \multicolumn{2}{|c|}{ Point value in Euros } & \multirow{2}{*}{ Adjustment factor for east Germany } \\
\hline & West Germany & East Germany & \\
\hline 1991 & $20.74(25.32)$ & $13.59(15.78)$ & 1.37 \\
\hline 1992 & $21.80(25.32)$ & $13.59(15.78)$ & 1.44 \\
\hline 1993 & $22.75(25.31)$ & $16.45(18.30)$ & 1.32 \\
\hline 1994 & $23.52(25.48)$ & $17.63(19.10)$ & 1.27 \\
\hline 1995 & $23.64(25.16)$ & $18.58(19.79)$ & 1.23 \\
\hline 1996 & $23.86(25.04)$ & $19.62(20.59)$ & 1.22 \\
\hline 1997 & $24.26(24.76)$ & $20.71(21.33)$ & 1.21 \\
\hline 1998 & $24.36(24.71)$ & $20.90(21.33)$ & 1.21 \\
\hline 1999 & $24.69(24.69)$ & $21.48(21.78)$ & 1.21 \\
\hline 2000 & $24.84(24.35)$ & $21.61(21.61)$ & 1.20 \\
\hline 2001 & $25.31(24.48)$ & $22.06(21.63)$ & 1.20 \\
\hline 2002 & $25.86(24.75)$ & $22.70(21.95)$ & 1.20 \\
\hline 2003 & $26.13(24.60)$ & $22.97(21.98)$ & 1.19 \\
\hline 2004 & $26.13(24.13)$ & $22.97(21.63)$ & 1.19 \\
\hline 2005 & $26.13(23.75)$ & $22.97(21.21)$ & 1.18 \\
\hline 2006 & $26.13(23.75)$ & $22.97(20.88)$ & 1.18 \\
\hline 2007 & $26.27(23.33)$ & $23.09(20.51)$ & 1.18 \\
\hline
\end{tabular}

Notes: Non-parenthesized figures are nominal and figures in parentheses have been converted into year 2000 prices using the Retail Price Index.

\section{A.2.2 Accumulation of Pension Points}

In addition to the pension point accumulation methods detailed in Section 2.4.3, individuals may be awarded further pension points in recognition of child-rearing. Specifically, one parent, normally the mother, is credited with one pension point for each child born before 1992 and three pension points for each child born more recently. Although we restrict our sample to men 
and women who are currently living without dependent children, it is possible that members of our sample cared for children earlier in their lives. Reflecting the possibilities for individuals to gain pension points for child-rearing, in the empirical implementation of the model we credit all women who had at least one child prior to entering the sample with 3 additional pension points. The German legislation further specifies that individuals may be awarded additional pension points for vocational training, university education, military or community service and provision of care for relatives. We neglect these additional pension points in our analysis.

\section{A.2.3 Eligibility for Early Retirement and Adjustments to Public Pension Benefits for Early Retirees}

As noted in Section 2.4.3, the eligibility criteria for early retirement depend on gender, disability status, working history and age. We provide here further details regarding the eligibility criteria for early retirement. In addition, we describe the year-specific rules that define the value of public pension benefits received by early retirees. We reiterate that all of these details are fully incorporated into our implementation of the above described life-cycle model.

Individuals aged under 60 years who are able to demonstrate sufficiently poor health can receive a disability pension. The value of the disability pension is proportional to the cumulative value of the weighted pension points that the individual would have received if he or she had remained in employment until age 60 years, with the proportionality factor being the same as that used to determine the value of public pension benefits for individuals retiring at the full pensionable age. Additionally, individuals aged over 60 years who are able to demonstrate sufficiently poor health can take early retirement and thus claim public pension benefits. Prior to 2002 , such individuals received a "non-reduced public pension", the value of which is obtained by multiplying the individual's weighted pension points accumulated at the time of retirement by the same proportionality factor as used to determine the value of public pension benefits for individuals retiring at the full pensionable age. More recently, the non-reduced public pension has only been available to individuals with sufficiently poor heath aged 63 years or over at the date of retirement. Meanwhile, those entering early retirement between the ages of 60 and 63 years due to poor health have received a reduced public pension. The value of the reduced public pension is obtained by applying a penalty to the non-reduced pension of $3.6 \%$ for every year that the individual's age upon retirement is below the full pensionable age of 65 years. This adjustment is less than actuarially fair.

In addition, prior to 1999, women aged 60 years and above and men with sufficiently long service histories (defined as at least 35 years of work experience) aged 63 years or over at the date of retirement were able to retire and receive a non-reduced public pension. Legislative reforms in 1992 and 1999 increased the age requirement for retirement on a non-reduced public pension to 65 years for healthy men and women, and also introduced the right to early retirement from age 60 years on a reduced public pension for individuals with long service histories. The value of the reduced public pension is obtained by applying a penalty of $3.6 \%$ to the non-reduced pension for every year that the individual's age upon retirement is below the full pensionable age of 65 years. The phase-in period for the 1992 legislation commenced in 1997 and the combined 1992 and 1999 reforms will be fully effective by 2017. See Bonin (2009) for further details. 


\section{A.2.4 Expectations Concerning the Future Public Pension System}

As explained in footnote 13, we assume that individuals expect the cohort-specific rules that define the public pension system to be maintained. We describe here the public pension reforms that occurred during the sample period and we argue that our modeling approach does not neglect any important anticipated future changes in the public pension system.

Recent pension reforms have the potential to alter the generosity of future public pension benefits. Specifically, recent reforms have: (i) increased the full pensionable age from 65 to 67 years; (ii) changed the eligibility requirements for early retirement and reduced the generosity of the public pension for some groups of early retirees; and (iii) changed the value of the proportionality factor, via the introduction of a "sustainability factor". The implications for the current study of the increase in the full pensionable age were discussed above in footnote 24 . Regarding the treatment of those who wish to retire early, we note that reforms to either the rules governing eligibility for early retirement or the adjustments made to the value of public pension benefits received by early retirees have always been announced many years in advance. Therefore, these changes have not affected the pension system applicable to individuals aged over 40 years at the time of their announcement. It is therefore entirely realistic for us to assume that the sample members, who are all aged 40 years or above, expect that the rules applicable to their particular birth cohort will persist into the future.

Finally, the sustainability factor, introduced in 2005, constitutes an adjustment to the proportionality factor and is designed to allow the public pension system to accommodate demographic changes and business cycle effects. Specifically, the sustainability factor depends on the ratio of the earnings of working individuals to the number of retired individuals, and acts to reduce the generosity of public pension benefits if this ratio decreases. It is anticipated that in the long-run the sustainability factor will work to reduce the value of public pension benefits. However, the short-run effects of the sustainability factor are unclear. Indeed, via the sustainability factor, a recent rise in female labor force participation caused an increase in the value of public pension benefits. We therefore consider it unlikely that the introduction of the sustainability factor will thus far have affected strongly individuals' expectations concerning future public pension benefits. Moreover, the sustainability factor was introduced in 2005, which is towards the end of our sample period. For these reasons, we neglect the sustainability factor in our analysis. 


\section{B Value Function Approximation}

Our method for approximating the value functions appearing in the life-cycle optimization problem is based on recursive simulation and interpolation, as first introduced by Keane and Wolpin (1994). In particular, we start with a set of randomly selected grid of points, where each grid point represents a particular combination of age 64.75 years state variables and an age 64.75 employment and consumption choice. The age 64.75 years state variables are then updated to the age 65 years values in accordance with the evolution of the underlying variables as specified by the structural model. Next, we evaluate the age 65 years value function at each point in the grid of age 65 years state space points; at age 65 years all individuals are retired and therefore computation of the age 65 years value function is straight forward and follows from equation (12). The results of an Ordinary Least Squares (OLS) regression are used to express the expected age 65 years value function in terms of variables known to the individual at age 64.75 years. This OLS regression, as well as those used in later value function approximations, includes a total of 143 regressors and is implemented using a grid containing 5000 points.

At the next stage of the value function approximation, we move back one quarter to age 64.5 years, update the state space variables to the age 64.75 values, and compute the age 64.75 years value function associated with each age 64.75 years choice possibility. Consumption, or equivalently, savings, is a continuous choice variable and therefore implementation of this method requires discretization of the choice set. We achieve this by restricting attention to the following choices: (i) employment in conjunction with savings of -500, 0, 500, 1000 and 2000 Euros per month; (ii) unemployment in conjunction with savings of $-2000,-1000,-500,0$, and 500 Euros per month; and (iii) retirement. We construct the choice set to over-represent dissaving combined with unemployment and saving combined with employment because these are the most prevalent combinations of savings and labor supply choices. ${ }^{47}$ We replace the expected age 65 years value function appearing in the age 64.75 choice-specific value functions with the approximation obtained previously. The maximum of the age 64.75 years choice-specific value functions is regressed on variables known to the individual at age 64.5 years. The regression results express the expected maximum of the age 64.75 years choice-specific value functions in terms of variables known to the individual at age 64.5 years. We continue backwards recursively in this way until we reach age 40 years. To ensure that we capture the year-specific aspects of the fiscal legislation, this entire procedure is repeated for each of the 17 different tax and transfer systems operational during the sample period.

\footnotetext{
${ }^{47}$ Importantly, as choices are made a quarterly intervals, the set of permitted annualized choices is much larger than the set of quarterly choices.
} 


\section{Moments}

Table 9: Summary of moments

\begin{tabular}{|c|c|c|}
\hline Description of moments & $\begin{array}{c}\text { Number } \\
\text { of moments }\end{array}$ & Primarily identifying \\
\hline $\begin{array}{l}\text { Wealth over the life-cycle: age-specific wealth levels and } \\
\text { wealth levels by gender and region }\end{array}$ & 29 & $\begin{array}{l}\text { Subjective time discount factor }(\delta) \text { and } \\
\text { curvature parameter }(\rho)\end{array}$ \\
\hline $\begin{array}{l}\text { Coefficients from an OLS regression of annual wealth change } \\
\text { on age }\end{array}$ & 2 & As above \\
\hline $\begin{array}{l}\text { Coefficient on life expectancy from an OLS regression of re- } \\
\text { tirement on life expectancy and controls for gender, region, } \\
\text { education, cohort and age }\end{array}$ & 1 & As above \\
\hline $\begin{array}{l}\text { Coefficients from an OLS regression of log wages on experi- } \\
\text { ence, health, initial employment, region, education, nation- } \\
\text { ality, gender and age terms }\end{array}$ & 14 & Distribution of offered wages \\
\hline $\begin{array}{l}\text { Distribution of log wages: percentiles of log wages and an- } \\
\text { nual changes in log wages; } 1^{\text {st }} 2^{\text {nd }} \text { and } 3^{\text {rd }} \text { order autocorre- } \\
\text { lations in annual log wages }\end{array}$ & 19 & As above \\
\hline $\begin{array}{l}\text { Treatment effects obtained from OLS regressions of transi- } \\
\text { tions between labor market states on the change in UI enti- } \\
\text { tlement period caused by the } 1997 \text { UI reform (see Haan and } \\
\text { Prowse, 2010) }\end{array}$ & 20 & Coefficient on consumption $(\beta)$ \\
\hline $\begin{array}{l}\text { Coefficients on initial employment state from OLS regres- } \\
\text { sions of employment and retirement on initial employment } \\
\text { state }\end{array}$ & 2 & $\begin{array}{l}\text { Variance of complementarity between } \\
\text { consumption and leisure }\left(\sigma_{\eta}\right)\end{array}$ \\
\hline $\begin{array}{l}\text { Persistence in labor market status: frequencies of various } \\
\text { sequences of transitions }\end{array}$ & 18 & $\begin{array}{l}\text { Parameters appearing in the job offer } \\
\text { and involuntary separation probabili- } \\
\text { ties }\end{array}$ \\
\hline $\begin{array}{l}\text { Labor supply over the life-cycle: age-specific employment } \\
\text { and retirement rates }\end{array}$ & 50 & $\begin{array}{l}\text { Mean of the complementarity parame- } \\
\text { ter }\left(\mu_{\eta}\right) \text { and age effects in the job of- } \\
\text { fer and involuntary separation proba- } \\
\text { bilities }\end{array}$ \\
\hline $\begin{array}{l}\text { Coefficients from OLS regressions of the individual-specific } \\
\text { numbers of transitions from unemployment to employment } \\
\text { and from employment to unemployment on initial employ- } \\
\text { ment state; Correlation between individual-specific numbers } \\
\text { of transition into and out of employment }\end{array}$ & 3 & $\begin{array}{l}\text { Variance-covariance matrix of the } \\
\text { individual-specific unobservables in } \\
\text { the job offer and involuntary separa- } \\
\text { tion probabilities }\left(\Sigma^{\eta}\right)\end{array}$ \\
\hline $\begin{array}{l}\text { Coefficients from OLS regressions of transitions from unem- } \\
\text { ployment to employment and from unemployment to retire- } \\
\text { ment on experience, health, UI entitlement period, region, } \\
\text { and age terms }\end{array}$ & 30 & $\begin{array}{l}\text { Parameters determining eligibility for } \\
\text { early retirement on the grounds of dis- } \\
\text { ability }\end{array}$ \\
\hline
\end{tabular}

Coefficients from OLS regressions of transitions from employment to unemployment and from employment to retirement on experience, health, UI entitlement period, region, and age terms

Coefficients from OLS regressions of initial employment and initial retirement on initial experience, initial health, gender, region, education, nationality, children, martial status, age terms and cohort effects

Coefficients from an OLS regression of initial wealth on initial employment, initial experience, gender, region and age terms; Standard deviation of initial wealth

$28 \quad$ As above

Notes: In the above descriptions of regressors, "region" is an indicator of the individual residing is west Germany. "Health" is an indicator of the individual having health problems that limit daily activities. "Gender" is an indicator of the individual being male. "Education" refers to years of education. "Nationality" is an indicator of the individual being a native German. "Children" and "marital status" are indicators of, respectively, the individual having had dependent children prior to entering the sample and having been married prior to entering the sample. "UI" is an abbreviation for Unemployment Insurance. 


\section{Initial Conditions}

The intertemporal linkages in our model, arising from the public pension and Unemployment Insurance systems, the endogenous accumulation of experience, and employment state dependent job opportunities, imply that in-sample wages and employment outcomes depend on the initial observations of experience, wages, wealth and employment status. Moreover, the presence of persistent unobservables in wages, in preferences and in the job offer and involuntary separation probabilities renders the first observations of experience, wages, wealth and employment status endogenous with respect to the persistent unobservables that drive subsequent behavior. In order to obtain consistent estimates of the structural parameters, despite the endogeneity of the initial conditions, we proceed in the spirit of Heckman (1981). Specifically, we approximate behavior prior to the sample period using a reduced form model in which the pre-sample endogenous variables may depend on the persistent unobservables that affect behavior during the sample period. The parameters appearing in the initial conditions are estimated jointly with the structural parameters.

In more detail, when implementing our MSM estimation method, we used a multinomial logit model in order to simulate employment and retirement outcomes for each individual in each quarter between leaving full-time education and entering the sample. The payoffs in the multinomial logit model depend on observed individual characteristics, the quarter-specific wage, cohort effects, and the permanent unobservables that feature in preferences and in the job offer and involuntary separation probabilities. When simulating behavior prior to the sample period, quarter-specific wages are obtained by taking draws from the distribution of offered wages as described by the structural parameters. Using the simulated pre-sample employment outcomes and wages we are able to construct each individual's experience, Unemployment Insurance entitlement period and pension points at the time when the individual enters the sample. Finally, we simulate initial wealth by drawing from a $\log$ normal distribution with a variance $\sigma_{\text {Wealth }}^{2}$ and a mean that depends on the individual's initial experience and initial employment state, as well as on age, gender, education and region of residence. Note that, via dependencies on pre-sample employment behavior and wages, the simulated values of initial experience, the initial Unemployment Insurance entitlement period, initial pension points and initial wealth are allowed to be endogenous with respect to behavior during the sample period.

Marital status and household structure prior to the individual entering the sample perform the role of exclusion restrictions, that is variables that affect the initial conditions but which, conditional on initial behavior, do not affect outcomes during the sample period. Examination of the relevant moments reveals that the excluded variables jointly have a significant effect on initial employment and initial retirement behavior ( $\chi^{2}$ test; $p=0.001$ ). Table 10 presents our estimates of the parameters appearing in the initial conditions. 
Table 10: Estimates of parameters appearing in the initial conditions

\begin{tabular}{|c|c|c|}
\hline & Coefficient & Standard Error \\
\hline \multicolumn{3}{|l|}{ Initial Employment } \\
\hline Intercept & 1.943 & 0.348 \\
\hline$($ Age -40$) \mathrm{I}(40 \leq$ Age $<55) / 15$ & -2.031 & 0.399 \\
\hline$($ Age -55$) \mathrm{I}($ Age $\geq 55) / 15$ & -4.990 & 0.830 \\
\hline $\log ($ gross offered wage $)$ & 2.605 & 0.453 \\
\hline Permanent unobserved individual preference shifter & 2.717 & 0.649 \\
\hline Permanent unobserved individual effect appearing in involuntary separation prob. & 0.002 & 0.147 \\
\hline Permanent unobserved individual effect appearing in job offer prob. & -2.694 & 0.349 \\
\hline Male & 0.211 & 1.074 \\
\hline West & 0.109 & 0.693 \\
\hline West $\times$ Male & 0.100 & 1.464 \\
\hline Education (years)/10 & 1.763 & 0.484 \\
\hline Year of birth $\times$ West $\times$ Male & -0.443 & 0.534 \\
\hline Year of birth $\times$ West $\times$ Female & 0.215 & 0.586 \\
\hline Year of birth $\times$ East $\times$ Male & 0.449 & 1.046 \\
\hline Year of birth $\times$ East $\times$ Female & 0.946 & 1.230 \\
\hline Native German & -0.494 & 0.359 \\
\hline Previously been married $^{\dagger}$ & 0.207 & 1.115 \\
\hline Previously had children $^{\dagger}$ & 0.350 & 1.273 \\
\hline Previously been married $\times$ West $^{\dagger}$ & -0.951 & 0.965 \\
\hline Previously been married $\times$ Male $^{\dagger}$ & -0.590 & 0.725 \\
\hline Previously had children $\times$ West $^{\dagger}$ & -0.226 & 1.255 \\
\hline Initial health problems & -1.637 & 0.383 \\
\hline \multicolumn{3}{|l|}{ Initial Retirement } \\
\hline Intercept & -3.374 & 0.267 \\
\hline$($ Age -54$) \mathrm{I}(54 \leq$ Age $<58) / 5$ & 0.115 & 0.621 \\
\hline$($ Age -58$) \mathrm{I}($ Age $\geq 58) / 5$ & 2.723 & 0.367 \\
\hline Male & -0.770 & 0.665 \\
\hline West & -1.283 & 0.408 \\
\hline West $\times$ Male & 1.192 & 0.758 \\
\hline Year of birth $\times$ West $\times$ Male & 0.516 & 0.651 \\
\hline Year of birth $\times$ West $\times$ Female & 1.163 & 0.480 \\
\hline Year of birth $\times$ East $\times$ Male & -1.949 & 3.344 \\
\hline Year of birth $\times$ East $\times$ Female & 0.264 & 0.799 \\
\hline Initial health problems & 1.901 & 0.385 \\
\hline \multicolumn{3}{|l|}{ Initial Wealth } \\
\hline Intercept & 7.375 & 0.135 \\
\hline$($ Age -40$) \mathrm{I}(40 \leq$ Age $<55) / 10$ & 0.969 & 0.168 \\
\hline$($ Age -55$) \mathrm{I}(55 \leq$ Age $<60) / 5$ & 0.353 & 0.180 \\
\hline$($ Age -60$) \mathrm{I}($ Age $\geq 60) / 5$ & 0.315 & 0.210 \\
\hline Male & -0.161 & 0.237 \\
\hline West & 1.156 & 0.155 \\
\hline West $\times$ Male & 0.376 & 0.268 \\
\hline Education (years)/10 & 1.096 & 0.142 \\
\hline Initial experience & 0.110 & 0.210 \\
\hline Initially employed & 0.432 & 0.121 \\
\hline$\sigma_{\text {Wealth }}$ & 1.169 & 0.033 \\
\hline
\end{tabular}

Notes: ${ }^{\dagger}$ denotes an exclusion restriction. The exclusion restrictions in the initial employment equation are jointly significant $\left(\chi^{2}\right.$ test; $\left.p=0.010\right)$. "Initial health problems" is an indicator of an individual having health problems that limit daily activities in the initial period of observation. 


\section{E Model Fit}

Figure 4: Fit of observed life-cycle behavior

(a) Employment

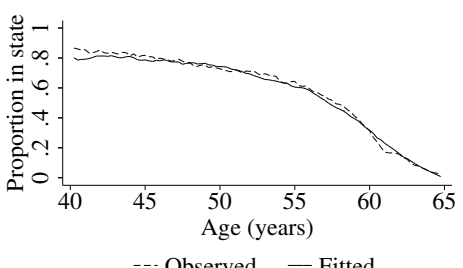

(d) Probability of exiting unemployment to employment

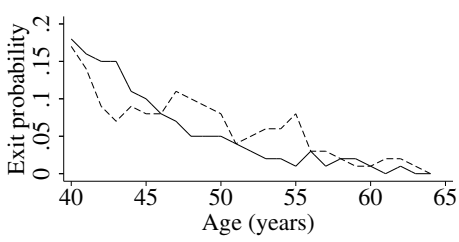

-- Observed - Fitted (b) Unemployment

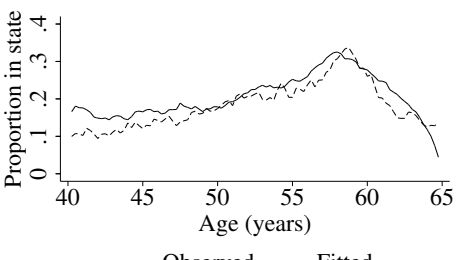

--. Observed — Fitted

(e) Probability of exiting employment to unemployment

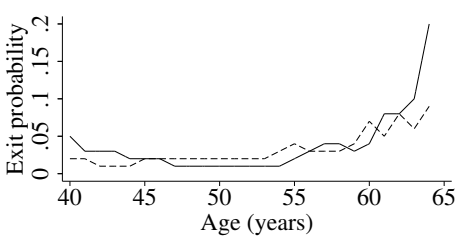

--. Observed — Fitted (c) Retirement

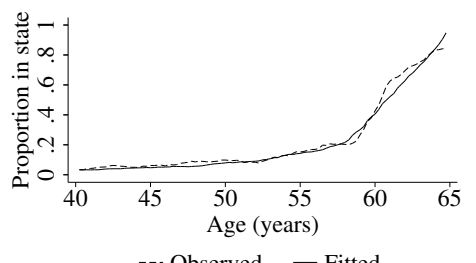

(f) Wealth (non-retired individuals)

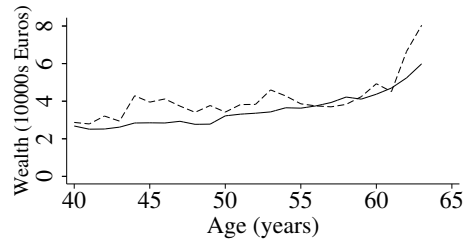

-.- Observed - Fitted

Notes: "Observed" refers to a value observed in the sample while "Fitted" refers to the value of the applicable quantity averaged over 5 simulated data sets.

Table 11: Fit of log wages and changes in log wages

\begin{tabular}{|c|c|c|c|c|c|c|c|c|}
\hline & $\mathrm{P}_{20}\left(w^{*}\right)$ & $\mathrm{P}_{40}\left(w^{*}\right)$ & $\mathrm{P}_{60}\left(w^{*}\right)$ & $\mathrm{P}_{80}\left(w^{*}\right)$ & $\mathrm{P}_{20}\left(\Delta^{1} w^{*}\right)$ & $\mathrm{P}_{40}\left(\Delta^{1} w^{*}\right)$ & $\mathrm{P}_{60}\left(\Delta^{1} w^{*}\right)$ & $\mathrm{P}_{80}\left(\Delta^{1} w^{*}\right)$ \\
\hline Fitted & -0.011 & 0.201 & 0.388 & 0.607 & -0.076 & -0.016 & 0.022 & 0.082 \\
\hline Observed & -0.034 & 0.194 & 0.394 & 0.650 & -0.080 & -0.016 & 0.020 & 0.098 \\
\hline SE & 0.020 & 0.016 & 0.017 & 0.026 & 0.005 & 0.001 & 0.002 & 0.006 \\
\hline \multirow[t]{2}{*}{ t-value } & 1.162 & 0.411 & -0.356 & -1.627 & 0.845 & 0.034 & 1.069 & -2.446 \\
\hline & $\mathrm{P}_{20}\left(\Delta^{2} w^{*}\right)$ & $\mathrm{P}_{40}\left(\Delta^{2} w^{*}\right)$ & $\mathrm{P}_{60}\left(\Delta^{2} w^{*}\right)$ & $\mathrm{P}_{80}\left(\Delta^{2} w^{*}\right)$ & $\mathrm{P}_{20}\left(\Delta^{3} w^{*}\right)$ & $\mathrm{P}_{40}\left(\Delta^{3} w^{*}\right)$ & $\mathrm{P}_{60}\left(\Delta^{3} w^{*}\right)$ & $\mathrm{P}_{80}\left(\Delta^{3} w^{*}\right)$ \\
\hline Fitted & -0.096 & -0.018 & 0.033 & 0.107 & -0.101 & -0.019 & 0.041 & 0.122 \\
\hline Observed & -0.087 & -0.017 & 0.034 & 0.121 & -0.084 & -0.008 & 0.053 & 0.134 \\
\hline $\mathrm{SE}$ & 0.006 & 0.003 & 0.003 & 0.009 & 0.008 & 0.005 & 0.005 & 0.009 \\
\hline t-value & -1.399 & -0.212 & -0.531 & -1.497 & -2.174 & -1.960 & -2.217 & -1.361 \\
\hline
\end{tabular}

Notes: $\mathrm{P}_{j}\left(w^{*}\right)$ refers to the $j^{\text {th }}$ percentile of log wages and $\mathrm{P}_{j}\left(\Delta^{r} w^{*}\right)$ denotes the $j^{\text {th }}$ percentile of the $r^{\text {th }}$ annual difference in log wages. "Observed" refers to a value observed in the sample while "Fitted" refers to the value of the applicable quantity averaged over 5 simulated data sets. "SE" is the standard error of the observed quantity (obtained via bootstrapping with clustering at the individual level) and "t-value" is the t-value for the test of equality of the observed and fitted quantities. 


\section{References}

Alesina, A. and Fuchs-Schuendeln, N. (2007). Good Bye Lenin (Or Not?): The Effect of Communism on People's Preferences. American Economic Review, 97(4): 1507-1528

Altonji, J. and Segal, L. (1996). Small-Sample Bias in GMM Estimation of Covariance Structures. Journal of Business and Economic Statistics, 14(3): 353-366

Blau, D. (1994). Labor Force Dynamics of Older Men. Econometrica, 62(1): 117-156

Blöndal, S. and Scarpetta, S. (1997). Early Retirement in OECD Countries: The Role of Social Security Systems. OECD Economic Studies, 29: 7-54

Blundell, R., Meghir, C., and Smith, S. (2002). Pension Incentives and the Pattern of Early Retirement. The Economic Journal, 112(478): C153-C170

Bonin, H. (2009). 15 Years of Pension Reform in Germany: Old Successes and New Threats. Geneva Papers on Risk and Insurance, 34: 548-560

Brown, J. (2001). Private Pensions, Mortality Risk, and the Decision to Annuitize. Journal of Public Economics, 82(1): 29-62

Börsch-Supan, A. and Schnabel, R. (1998). Social Security and Declining Labor-Force Participation in Germany. American Economic Review: Papers and Proceedings, 88(2): 173178

Börsch-Supan, A. and Wilke, C. (2004). The German Public Pension System: How it Was, How it Will Be. NBER Working Paper 10525

Casanova, M. (2010). Happy Together: A Structural Model of Couples' Joint Retirement Choices. Mimeo

De Nardi, M., French, E., and Jones, J. (2009). Life Expectancy and Old Age Savings. American Economic Review: Papers and Proceedings, 99(2): 110-115

De Nardi, M., French, E., and Jones, J. (2010). Why do the Elderly Save? The Role of Medical Expenses. Journal of Political Economy, 118(1): 39-75

Disney, R. and Smith, S. (2002). The Labour Supply Effect of the Abolition of the Earnings Rule for Older Workers in the United Kingdom. The Economic Journal, 112(478): C136-C152

Eckstein, Z. and Wolpin, K.I. (1989). Dynamic Labour Force Participation of Married Women and Endogenous Wage Growth. Review of Economic Studies, 56(3): 375-390

French, E. (2005). The Effects of Health, Wealth, and Wages on Labour Supply and Retirement Behaviour. Review of Economic Studies, 72(2): 395-427

French, E. and Jones, J. (2010). Public Pensions and Labor Supply over the Life Cycle. Federal Reserve Bank of Chicago, Working Paper 2010-09

French, E. and Jones, J. (forthcoming). The Effects of Health Insurance and Self-Insurance on Retirement Behavior. forthcoming in Econometrica

Friedberg, L. (2000). The Labor Supply Effects of the Social Security Earnings Test. Review of Economics and Statistics, 82(1): 48-63

Friedberg, L. and Webb, A. (2005). Retirement and the Evolution of Pension Structure. Journal of Human Resources, 40(2): 281-308

Fuchs-Schuendeln, N. (2008). The Response of Household Saving to the Large Shock of German Reunification. The American Economic Review, 98(5): 1798-1828

Fuchs-Schuendeln, N. and Schuendeln, M. (2005). Precautionary Savings and SelfSelection: Evidence from the German Reunification Experiment. Quarterly Journal of Economics, 120(3): 1085-1120

Gan, L., Gong, G., Hurd, M., and McFadden, D. (2004). Subjective Mortality Risk and Bequests. NBER Working Paper, 10789

Gjonça, A., Brockmann, H., and Maier, H. (2000). Old-Age Mortality in Germany Prior to and After Unification. Demographic Research, 3(1)

Gourinchas, P. and Parker, J. (2002). Consumption Over the Life Cycle. Econometrica, 70(1): 47-89

Gruber, J. and Wise, D. (1998). Social Security and Retirement: An International Compar- 
ison. The American Economic Review: Papers and Proceedings, 88(2): 158-163

Gruber, J. and Wise, D. (2004). Social Security Programs and Retirement Around the World: Micro-estimation. University of Chicago Press

Gruber, J. and Wise, D. (2007). Social Security Programs and Retirement Around the World: Fiscal Implications for Reform. University of Chicago Press

Gustman, A.L. and Steinmeier, T.L. (1986). A Structural Retirement Model. Econometrica, 54(3): $555-584$

Gustman, A.L. and Steinmeier, T.L. (2005). The Social Security Early Entitlement Age in a Structural Model of Retirement and Wealth. Journal of Public Economics, 89(2-3): 441-463

Haan, P. and Prowse, V. (2010). The Design of Unemployment Transfers - Evidence from a Dynamic Structural Life-cycle Model. Working Paper, Department of Economics, University of Oxford, 478

Haveman, R., De Jong, P., and Wolfe, B. (1991). Disability Transfers and the Work Decision of Older Men. The Quarterly Journal of Economics, 106(3): 939-949

Heckman, J. (1981). Statistical Models for Discrete Panel Data. In C.F. Manski and D. McFadden, editors, Structural Analysis of Discrete Data with Econometric Applications, 114-178. MIT Press

Heyma, A. (2004). A Structural Dynamic Analysis of Retirement Behaviour in the Netherlands. Journal of Applied Econometrics, 19(6): 739-759

Hurd, M. (1989). Mortality Risk and Bequests. Econometrica, 57(4): 779-813

Jiménez-Martín, S. and Sanchez Martín, A. (2007). An Evaluation of the Life Cycle Effects of Minimum Pensions on Retirement Behavior. Journal of Applied Econometrics, 22(5): $923-950$

Johnson, N., Backlund, E., Sorlie, P., and Loveless, C. (2000). Marital Status and Mortality: The National Longitudinal Mortality Study. Annals of Epidemiology, 10(4): 224238

Keane, M.P. and Wolpin, K.I. (1994). The Solution and Estimation of Discrete Choice Dynamic Programming Models by Simulation and Interpolation: Monte Carlo Evidence. The Review of Economics and Statistics, 76(4): 648-672

Kibele, E. and Scholz, R. (2008). Trend der Mortalitätsdifferenzen in Ost und West unter Berücksichtigung der vermeidbaren Sterblichkeit, 125-140. VS Verlag für Sozialwissenschaften

Lalive, R., van Ours, J., and Zweimüller, J. (2006). How Changes in Financial Incentives Affect the Duration of Unemployment. Review of Economic Studies, 73(4): 1009-1038

Low, H., Meghir, C., and Pistaferri, L. (2010). Wage Risk and Employment Risk over the Life Cycle. American Economic Review, 100(4): 1432-1467

Nolte, E., Scholz, R., Shkolnikov, V., and McKee, M. (2002). The Contribution of Medical Care to Changing Life Expectancy in Germany and Poland. Social Science 63 Medicine, 55(11): 1905-1921

Oeppen, J. and Vaupel, J.W. (2002). Broken Limits to Life Expectancy. Science, 296(5570): 1029-1031

Pakes, A. and Pollard, D. (1989). Simulation and the Asymptotics of Optimization Estimators. Econometrica, 57(5): 1027-1057

Rust, J. and Phelan, C. (1997). How Social Security and Medicare Affect Retirement Behavior in a World of Incomplete Markets. Econometrica, 65(4): 781-832

Schmitz, H. and Steiner, V. (2007). Benefit-Entitlement Effects and the Duration of Unemployment: An Ex-ante Evaluation of Recent Labour Market Reforms in Germany. Technical report, DIW Berlin, German Institute for Economic Research, Number 678

van der Klaauw, W. and Wolpin, K.I. (2008). Social Security and the Retirement and Savings Behavior of Low-Income Households. Journal of Econometrics, 145(1-2): 21-42

Wagner, G., Frick, J., and Schupp, J. (2007). The German Socio-Economic Panel Study (SOEP) - Scope, Evolution and Enhancements. Schmollers Jahrbuch, 127(1): 139-169 